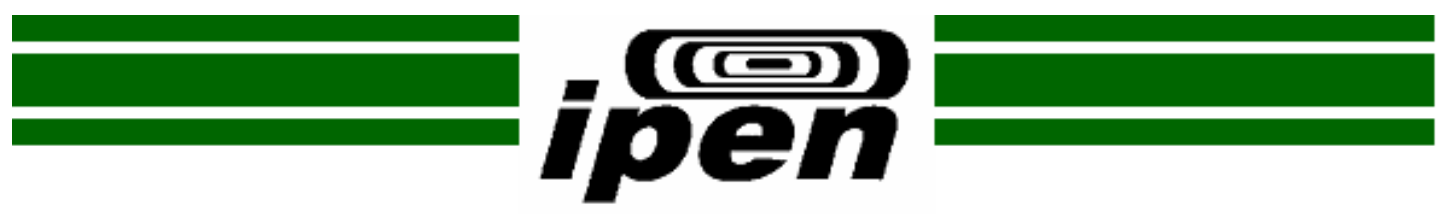

Autarquia associada à Universidade de São Paulo

\title{
ESTUDO SOBRE O GÁS OZÔNIO FORMADO NO PROCESSO DE IRRADIAÇÃO INDUSTRIAL COM COBALTO-60 E SEU IMPACTO NO MEIO AMBIENTE
}

\section{Daniel Henrique Uzueli}

Dissertação apresentada como parte dos requisitos para obtenção do Grau de Mestre em Ciências na Área de Tecnologia Nuclear - Aplicações.

Orientador:

Dr. Fábio Eduardo da Costa

São Paulo 
INSTITUTO DE PESQUISAS ENERGÉTICAS E NUCLEARES

Autarquia associada à Universidade de São Paulo

\section{ESTUDO SOBRE O GÁS OZÔNIO FORMADO NO PROCESSO DE IRRADIAÇÃO INDUSTRIAL COM COBALTO-60 E SEU IMPACTO NO MEIO AMBIENTE}

Daniel Henrique Uzueli

Dissertação apresentada como parte dos requisitos para obtenção do Grau de Mestre em Ciências na Área de Tecnologia Nuclear - Aplicações.

Orientador:

Dr. Fábio Eduardo da Costa

São Paulo 
Aos meus pais, à minha esposa e aos meus filhos pelo incentivo e paciência durante a realização deste trabalho. 


\section{AGRADECIMENTOS}

Ao Dr. Paulo Roberto Rela, pela idealização, contribuição e incentivo para a realização deste trabalho.

Ao Dr. Fábio Eduardo da Costa, pela amizade construída nesses anos e pela orientação neste trabalho contribuindo para meu crescimento científico e intelectual.

À Dra. Margarida Mizue Hamada, pela orientação no início do trabalho.

À Dra. Luciana Vanni Gatti, do Centro de Química e Meio Ambiente do IPEN / CNEN - SP, pelo equipamento cedido para o experimento.

A todos os colegas no Centro de Tecnologia das Radiações do IPEN / CNEN SP que contribuíram direta ou indiretamente para a realização deste trabalho.

Ao Instituto de Pesquisas Energéticas e Nucleares, pela oportunidade de realização do curso de mestrado. 


\title{
ESTUDO SOBRE O GÁS OZÔNIO FORMADO NO PROCESSO DE IRRADIAÇÃO INDUSTRIAL COM COBALTO-60 E SEU IMPACTO NO MEIO AMBIENTE
}

\author{
Daniel Henrique Uzueli
}

\section{RESUMO}

O processamento por radiação está presente em diversos produtos tais como: alimentos, materiais médicos descartáveis, cabos elétricos, gemas, entre outros. O uso da radiação tem a finalidade de melhorar as propriedades dos produtos, esterilizá-los ou higienizá-los. Nos irradiadores industriais, as radiações eletromagnéticas (gama e raios-X) ou de elétrons, antes de interagirem com os produtos em beneficiamento, encontram uma camada de ar. Ao interagirem com esta camada, provocam efeitos radiolíticos nas moléculas presentes na atmosfera ambiente, sendo a principal interação a que ocorre com as moléculas de oxigênio, que têm suas ligações quebradas, separando-se em dois átomos altamente reativos que, ao recombinarem com outra molécula de oxigênio, formam o gás ozônio. Neste trabalho foram estudadas a formação, o decaimento e a dispersão do ozônio em irradiadores industriais gama que utilizam como fonte de radiação o cobalto-60. O monitoramento da concentração de ozônio foi realizado pelo método de absorção óptica em um monitor comercial. 


\title{
STUDY ON OZONE GAS FORMED IN THE INDUSTRIAL RADIATION PROCESS WITH COLBAT-60 AND ITS IMPACT ON THE ENVIRONMENT
}

\author{
Daniel Henrique Uzueli
}

\begin{abstract}
The radiation processing is present in various products such as foods, medical disposables, electrical cables, gems, among others. This process aims to improve the properties, sterilize or sanitize irradiated products. In industrial irradiators facilities, electromagnetic radiation (gamma and X-rays) or electrons before they interact with the products in processing, there are a layer of air. To interact with this air layer, it causes radiolytic effects on the molecules present in the ambient atmosphere, and the main interaction are with the oxygen molecules that have their bonds broken, separating them into two highly reactive atoms that recombine with the other molecule of oxygen to form ozone gas. In this work it was studied the formation, decay and dispersion of ozone in industrial gamma irradiators facilities that use cobalt-60 as a source of radiation. The monitoring of ozone concentration was performed by optical absorption method in a commercial monitor.
\end{abstract}




\section{SUMÁRIO}

Página

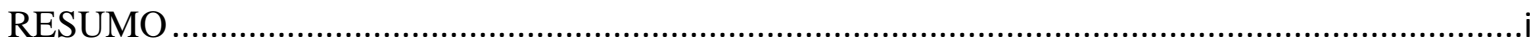

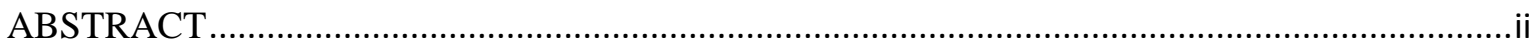

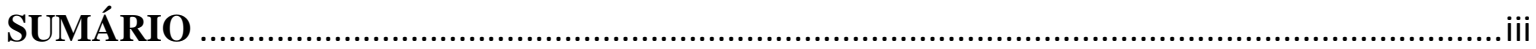

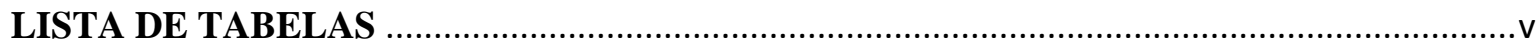

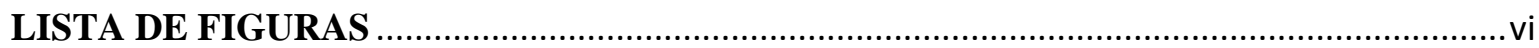

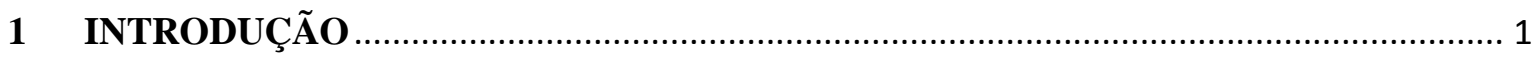

2 OBJETIVO

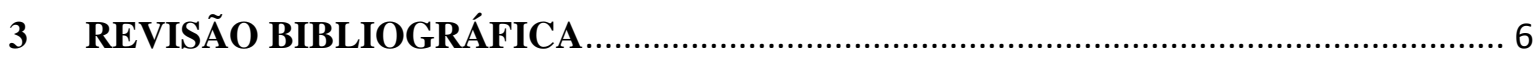

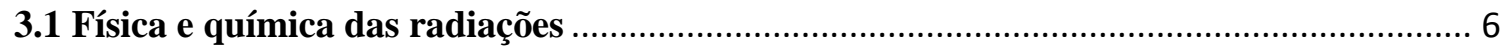

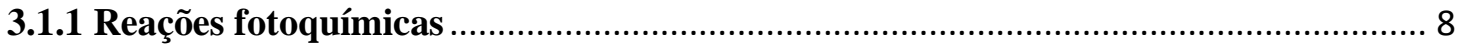

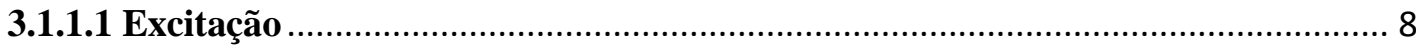

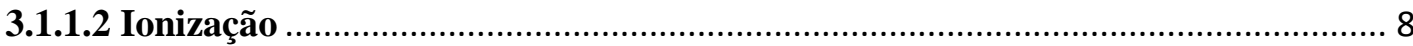

3.1.2 Interação de raios gama e raios-X com a matéria ................................................... 9

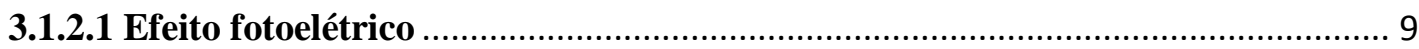

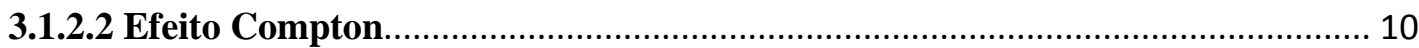

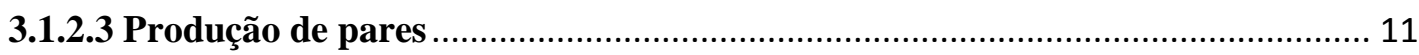

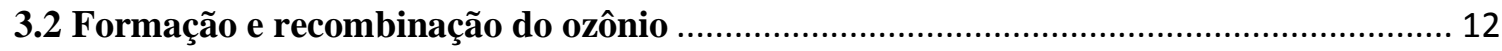

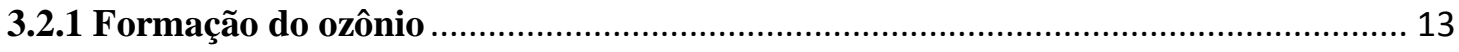

3.2.2 Recombinação do ozônio ………............................................................................... 14

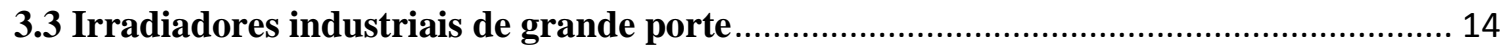

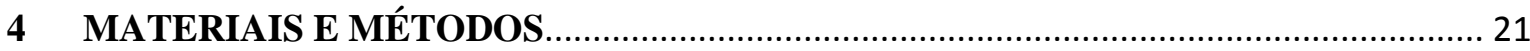

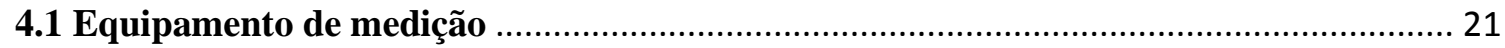

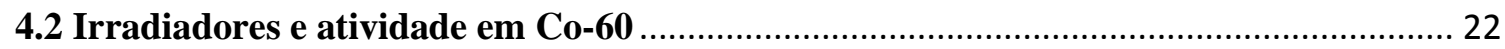

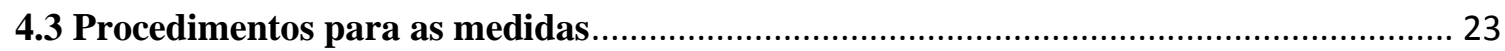

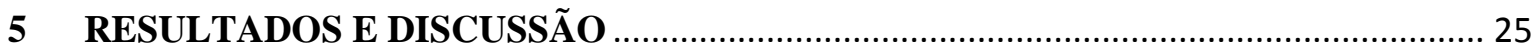

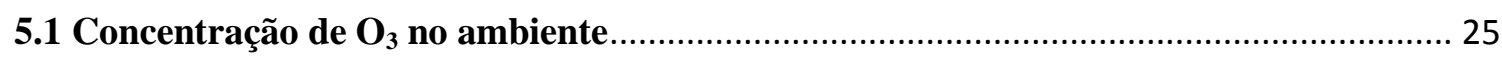

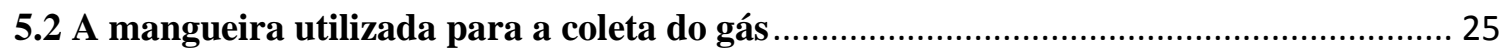

5.3 Medidas em condições normais de operação …….......................................................... 26 


\section{SUMÁRIO}

Página

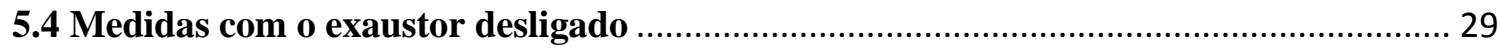

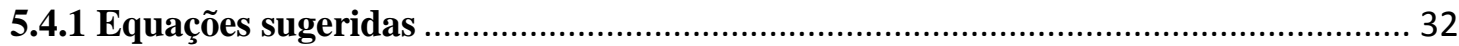

5.5 Medidas em condições normais de operação após o recolhimento das fontes ................. 39

5.6 Medidas da dispersão do $\mathrm{O}_{3}$ para o meio ambiente …....................................................... 41

5.7 Medidas ao longo do diâmetro interno da tubulação de exaustão .................................... 44

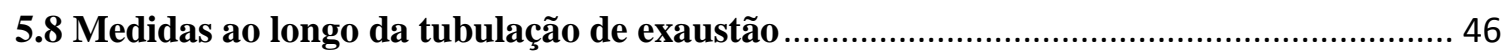

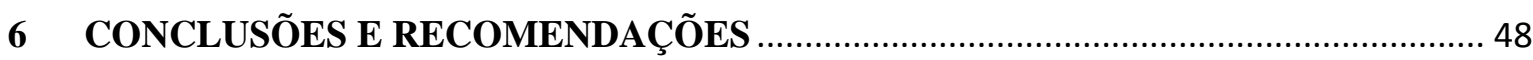

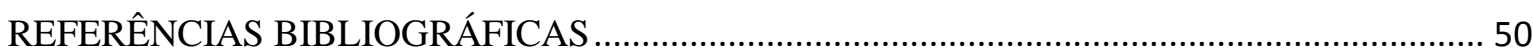




\section{LISTA DE TABELAS}

Página

Tabela 1 Valores de atividade em Co-60 disponível em cada instalação.

Tabela 2 Valores médios de concentração de equilíbrio de $\mathrm{O}_{3}$, obtidos nas tubulações de exaustão das instalações estudadas.

Tabela 3 Tempos de meia-vida para o decaimento do $\mathrm{O}_{3}$ no Irradiador Multipropósito do IPEN/CNEN-SP, para diferentes volumes ocupados.

Tabela 4 Valores de taxa de produção de $\mathrm{O}_{3}$ calculados e atividade dos bastidores na data do experimento no Irradiador Multipropósito do IPEN/CNEN-SP.

Tabela 5 Valores de concentração de $\mathrm{O}_{3}$ calculados na condição de equilíbrio e os valores medidos.

Tabela 6 Tempo para a concentração de $\mathrm{O}_{3}$ atingir o limite ocupacional 40 nas instalações.

Tabela 7 Valores de concentração de $\mathrm{O}_{3}$ nos pontos amostrados ao longo da tubulação de exaustão do Irradiador Multipropósito do IPEN/CNEN-SP. 


\section{LISTA DE FIGURAS}

Página

Figura 1 Representação esquemática da emissão de um raio gama.

Figura 2 Representação esquemática da emissão de raio-X: (a) 7 Bremsstrahlung e (b) raio- $X$ característico.

Figura 3 Representação esquemática do efeito fotoelétrico. 9

Figura 4 Representação esquemática do efeito Compton. 10

Figura 5 Representação esquemática da produção do par elétron-pósitron. 11

Figura 6 Distribuição da predominância de cada um dos três principais 12 meios de interação dos fótons com a matéria [46].

$\begin{array}{lll}\text { Figura } 7 & \text { Esquema de um irradiador gama categoria I pela AIEA [54]. } & 15\end{array}$

Figura 8 Esquema de um irradiador gama panorâmico categoria II pela 16 AIEA [53].

Figura 9 Esquema de um irradiador gama categoria III pela AIEA [53].

Figura 10 Esquema de um irradiador gama categoria IV pela AIEA [53]. 18

Figura 11 Foto do irradiador multipropósito de Co-60 tipo compacto do 19 IPEN/CNEN-SP.

Figura 12 Esquema em corte do Irradiador Multipropósito de Co-60 tipo 20 compacto do IPEN/CNEN-SP [5].

Figura 13 Esquema de funcionamento do monitor 49C da Thermo 22 Environmental Instruments [58].

Figura 14 Medidas tomadas nas tubulações de exaustão até a condição de 26 equilíbrio.

Figura 15 Valores de concentração na condição de equilíbrio em função das 28 atividades das fontes.

Figura 16 Valores de concentração na condição de equilíbrio em função das atividades das fontes no Irradiador Multipropósito do IPEN / CNEN - SP. 
Figura 17 Curvas de decaimento da concentração de $\mathrm{O}_{3}$ no nível do piso interno do Irradiador Multipropósito do IPEN/CNEN-SP para diferentes volumes ocupados e com a atividade máxima disponível na câmara de irradiação.

Figura 18 Curva de decaimento da concentração de $\mathrm{O}_{3}$ no nível do piso interno do Irradiador Multipropósito do IPEN/CNEN-SP, com a câmara vazia.

Figura 19 Concentração de $\mathrm{O}_{3}$ em função do tempo, na tubulação de exaustão em condições normais de operação. A curva em preto representam os valores medidos e a em vermelho os valores calculados utilizando a equação (1) proposta.

Figura 20 Valores de concentração de $\mathrm{O}_{3}$ na tubulação de exaustão operando com o bastidor 1. A curva em preto representam os valores medidos e a em vermelho os valores calculados utilizando a equação (4) proposta.

Figura 21 Valores de concentração de $\mathrm{O}_{3}$ na tubulação de exaustão operando com o bastidor 2. A curva em preto representam os valores medidos e a em vermelho os valores calculados utilizando a equação (4) proposta.

Figura 22 Curvas de decaimentos da concentração de $\mathrm{O}_{3}$, medidas após o recolhimento das fontes.

Figura 23 Desenho representativo das distâncias da coleta de amostras de $\mathrm{O}_{3}$ em relação à torre de exaustão do irradiador $\mathrm{A}$, a uma altura $\mathrm{h}=$ 6,5 m com relação ao solo.

Figura 24 Concentrações de $\mathrm{O}_{3}$ em função da distância da torre de exaustão no irradiador A, medidas a 6,5 m de altura em relação ao solo.

Figura 25 Desenho das posições medidas, no nível do solo, com relação à chaminé do irradiador A.

Figura 26 Concentrações de $\mathrm{O}_{3}$ em função da distância da torre de exaustão no irradiador A, medidas no nível do solo.

Figura 27 Desenho das posições de medidas da concentração de $\mathrm{O}_{3}$ ao longo do diâmetro interno da tubulação de exaustão.

Figura 28 Concentração de $\mathrm{O}_{3}$ medida ao longo do interior da tubulação de exaustão do Irradiador Multipropósito do IPEN/CNEN-SP.

Figura 29 Desenho dos pontos de coleta para determinação das concentrações de $\mathrm{O}_{3}$ ao longo da tubulação de exaustão do Irradiador Multipropósito do IPEN/CNEN-SP. 


\section{INTRODUÇÃO}

O processamento por radiação está presente em diversos produtos tais como: alimentos, materiais médicos descartáveis, cabos, gemas, entre outros. Este processo tem a finalidade de melhorar as propriedades e esterilizar ou higienizar os produtos irradiados.

As radiações ionizantes utilizadas em processos industriais podem ser classificadas em dois tipos: radiação eletromagnética e radiação na forma de partícula. A eletromagnética inclui os raios gama e os raios-X que se diferem pelo modo como são produzidos. Os raios-X são produzidos utilizando-se aceleradores de elétrons e se valem do fenômeno físico, no qual um elétron incidente passando próximo a um núcleo de um átomo tem a sua trajetória desviada com a emissão de um fóton, sendo este efeito conhecido como "Bremsstrahlung" [1-3].

Os raios gama são originados de transições do núcleo de átomos que se encontram em um nível energético superior e instável (isótopo radioativo), passando para um nível de menor energia e estável. Existem dois tipos de radioisótopos: os naturais (rádio, urânio, tório, etc.) e os artificiais produzidos em reatores nucleares e aceleradores de partículas. Nesta categoria encontra-se o cobalto-60 (Co-60), que é produzido por meio de uma reação nuclear na qual o isótopo cobalto-59 (Co-59), que é estável, é bombardeado com nêutrons no interior de um reator e o seu núcleo, ao receber um nêutron, altera o seu número de massa, transformando-o no isótopo Co-60, instável e radioativo, que, durante o seu decaimento, emite dois raios gamas com energias de $1,17 \mathrm{MeV}$ e 1,33 MeV [4,5].

No caso das radiações na forma de partículas, especificamente os elétrons agrupados em feixes, estes são produzidos em equipamentos que se assemelham a um tubo de televisão de raios catódicos, onde os elétrons são gerados por efeito termoelétrico e acelerados em um campo elétrico de alta intensidade até atingir o alvo ou produto. Em televisores com tubo, a tensão de aceleração é da ordem de 25.000 Volts e nos aceleradores industriais o campo elétrico pode chegar até 10.000.000 Volts, fazendo com que os elétrons sejam acelerados a uma energia de até $10 \mathrm{MeV}$ [4]. 
O bombardeamento de produtos por radiação gama, por raios-X ou por feixe de elétrons é uma técnica consolidada no processamento de materiais por radiação ionizante, sendo a principal diferença o tipo de radiação primária que interage com o produto a ser tratado [1]. Durante o processamento industrial por radiação gama ou raios-X, fótons de alta energia, ao interagirem com os produtos, produzem inicialmente elétrons rápidos os quais, por sua vez, produzem a maioria dos efeitos da radiação ionizante (efeito fotoelétrico, espalhamento Compton e produção de pares). No nível atômico, os efeitos desses fótons de alta energia são similares ou praticamente idênticos aos dos elétrons rápidos, produzidos por aceleradores de elétrons. Após a primeira interação, o mecanismo de transporte de energia no interior do produto é o mesmo para os três tipos de radiação, prevalecendo o efeito produzido pelos elétrons secundários (elétrons expulsos de suas órbitas) que produzem a maioria das excitações e ionizações provocando os efeitos químicos desejados [1,2].

Como resultado desse processo de transferência de energia, a principal aplicação industrial do processamento por radiação ionizante consiste na inativação de microorganismos pela radiação, a qual é ocasionada, em parte, pela ação da colisão direta da radiação com regiões sensíveis da célula e, parcialmente, pela ação indireta, via formação de radicais químicos altamente ativos, produzidos no líquido da célula pela radiação. Por exemplo, no caso da ação direta, a radiação ioniza uma parte da molécula de DNA, uma enzima ou qualquer outro componente vital da célula, levando-a a um estado de falência ou na inibição da sua reprodução. Pela via indireta, a radiação provoca nas moléculas de água, presentes nos microorganismos, a formação de radicais livres tais como: $\mathrm{OH}^{-}, \mathrm{H}^{+}$e moléculas como $\mathrm{H}_{2} \mathrm{O}_{2}$. Essas espécies químicas, por serem altamente reativas, podem interagir com os componentes vitais dos microorganismos causando indiretamente danos letais [4].

O processo de redução microbiológica ou esterilização por radiação traz vantagens quando comparado a processos convencionais como óxido de etileno ou autoclavagem. $\mathrm{O}$ processamento por radiação pode ser realizado na embalagem final do produto, na temperatura e pressão atmosférica em que o produto se encontra, em qualquer fase do produto (sólido, liquido ou gasoso), não deixa resíduos de gases e não há a necessidade de catalisadores [4-6]. Além da esterilização, o processamento por radiação pode melhorar as propriedades dos materiais, como polímeros, que tem a sua resistência térmica e mecânica 
melhoradas [7-9], gemas, que têm a sua coloração alterada após o processamento [10,11], e frutas e obras de arte, que são desinfeccionadas ou desinfestadas [12,13].

Nos irradiadores industriais as radiações eletromagnéticas (gama e raios-X) ou de elétrons, antes de interagirem com os produtos em beneficiamento, atravessam uma camada de ar. Ao interagirem com essa camada, provocam efeitos radiolíticos nos átomos presentes na atmosfera ambiente, sendo a principal a interação com os átomos de oxigênio. Essa interação é similar a que ocorre na estratosfera, segundo o Ciclo de Chapman [14], quando uma molécula diatômica do oxigênio $\left(\mathrm{O}_{2}\right)$ absorve radiação ultravioleta do sol com comprimento de onda inferior a 240 nanômetros, quebrando a ligação e separando-a em dois átomos altamente reativos, os quais, ao combinarem com outra molécula de oxigênio, formam o ozônio $\left(\mathrm{O}_{3}\right)$.

$\mathrm{O}$ valor de $240 \mathrm{~nm}$ (energia $=5,1 \mathrm{eV}$ ) é o limiar do comprimento de onda da radiação eletromagnética com um quanta de energia suficiente para provocar a reação fotoquímica de dissociação do $\mathrm{O}_{2}$ [14]. No caso dos irradiadores gama que utilizam o Co60, emitindo dois fótons com energias de 1,17 MeV e 1,33 MeV respectivamente, cada um desses fótons produz em média 15 elétrons por efeito Compton e um por efeito fotoelétrico [2]. Dos 16 elétrons, cerca de três terão energia cinética maior do que $0,1 \mathrm{MeV}$, cerca de três terão energia entre $0,03 \mathrm{MeV}$ e $0,1 \mathrm{MeV}$, cerca de sete entre 0,01 e $0,03 \mathrm{MeV}$ e cerca de três entre 0,001 e 0,01 MeV. Juntos esses elétrons provocarão cerca de 40.000 ionizações (com média de $30 \mathrm{eV}$ por ionização) [2]. Para irradiadores industriais que utilizam fontes de radiação gama com atividades superiores a centenas de $\mathrm{Ci}$, a taxa de formação de $\mathrm{O}_{3}$ é elevada, e o mesmo acontece nas instalações industriais com aceleradores com alto fluxo de elétrons onde a taxa de dose é da ordem de 2 × $10^{8}$ Gy/s [2].

$\mathrm{Na}$ troposfera, $\mathrm{o}_{3}$ atua como uma capa protetora, blindando a superfície da terra dos raios ultravioleta de alta energia provenientes do sol [15-18]. Mesmo a baixas concentrações $(0,01-0,05 \mathrm{ppm})$ o gás pode ser percebido por um odor característico [19]. Por ser altamente reativo, o $\mathrm{O}_{3}$ ao nível da superfície da terra é nocivo a plantas, animais e seres humanos [20-24]. A exposição crônica ao $\mathrm{O}_{3}$ pode causar alterações morfológicas, imunológicas, funcionais e bioquímicas ao pulmão e contribuir para a formação de tumores $[25,26]$. Nas instalações de irradiação com gama, raios-X ou aceleradores de elétrons, o $\mathrm{O}_{3}$ produzido interage com a superfície dos produtos tratados e com elementos estruturais dos irradiadores, sendo nociva a elevada concentração desse gás no interior de suas câmaras de irradiação, principalmente quando é necessário o acesso dos operadores para realizarem 
intervenção de manutenção ou posicionamento de produtos. Para tanto, faz-se necessária a instalação de algum sistema de exaustão para redução da concentração e posterior lançamento, dentro de níveis permitidos, desse gás ao meio ambiente.

No Brasil, o Conselho Nacional do Meio Ambiente (CONAMA) do Ministério do Meio Ambiente, por meio da resolução CONAMA $n^{\circ}$ 03/90 [27], define que a concentração média de $\mathrm{O}_{3}$ em uma hora deve ser inferior a $0,16 \mathrm{mg} / \mathrm{m}^{3}$, equivalente a 80 ppb de $\mathrm{O}_{3}$ no ar, e não deve ser excedida mais de uma vez por ano, enquanto o Ministério do Trabalho, por meio da norma regulamentadora NR n 15 [28], estabelece como limite de tolerância, que é considerado como excedido quando a média aritmética de dez amostragens, para um intervalo mínimo de vinte minutos por amostragem, a concentração de $0,16 \mathrm{mg} / \mathrm{m}^{3}$. Apenas como outro ponto de referência, a Agência de Proteção Ambiental Americana (EPA) estabeleceu em 2008 um novo limite nacional para a concentração de $\mathrm{O}_{3}, 0,075$ ppm calculado em uma média de 8 horas, após um extenso estudo sócioeconômico [29].

Os primeiros estudos sobre a formação de $\mathrm{O}_{3}$ por radiação datam de 1911 com Lind [30] em experimentos com partículas alfa. Durante a pesquisa bibliográfica foram encontrados experimentos conduzidos para a determinação de reações fotoquímicas e seus respectivos rendimentos na formação de $\mathrm{O}_{3}$ a partir da irradiação de amostras de $\mathrm{O}_{2}$ com parâmetros bem controlados [31-36], da irradiação de amostras de ar e misturas $\mathrm{N}_{2}-\mathrm{O}_{2}$ [37,38] e da interação da radiação de luz síncrotron com amostras de ar [39,40]. Foram encontrados dois trabalhos que relacionam a formação de $\mathrm{O}_{3}$ em aceleradores de elétrons e a taxa de extração de ar na instalação $[3,41]$ e dois trabalhos com medidas quantitativas de concentração de $\mathrm{O}_{3}$, um durante a operação de um acelerador de elétrons [42] e outro durante a operação de um acelerador cíclotron para a produção de radioisótopos [43]. Não foram encontrados trabalhos realizados em irradiadores industriais utilizando radiação gama, demonstrando a escassez de dados sobre o tema na literatura. 


\section{OBJETIVO}

O objetivo do presente trabalho é verificar o dimensionamento do sistema de exaustão de irradiadores industriais, considerando-se a taxa de formação e liberação de $\mathrm{O}_{3}$ para o meio ambiente em função da radiação incidente e das condições de operação da instalação.

Para isso foram determinados o tempo de meia-vida do $\mathrm{O}_{3}$ na instalação, a taxa de liberação de $\mathrm{O}_{3}$ para o meio ambiente e a dispersão do $\mathrm{O}_{3}$ no meio ambiente. 


\section{REVISÃO BIBLIOGRÁFICA}

\subsection{Física e química das radiações}

As radiações ionizantes podem ser classificadas em dois grupos [2]:

i) Radiação eletromagnética, tais como os raios gama e raios-X;

ii) Partículas, tais como elétrons, prótons e nêutrons.

No processamento industrial por radiação são utilizadas fontes de raios gama, raios$\mathrm{X}$ e feixe de elétrons. As energias envolvidas nesse tipo de processamento são abaixo dos limiares de energia necessários para provocarem reações nucleares, e, por isso, os materiais processados não se tornam radioativos.

As fontes de radiação gama emitem fótons com valores discretos de energia a partir do núcleo atômico na passagem de um estado excitado para um estado de menor energia [44-46], Figura 1.

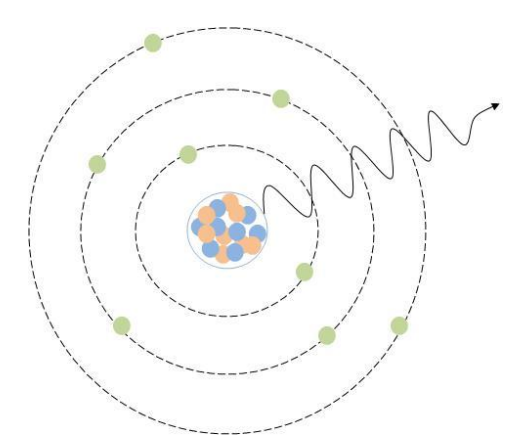

Figura 1 - Representação esquemática da emissão de um raio gama.

Os irradiadores industriais utilizam o radioisótopo Co-60, obtido por ativação do Co-59, em reatores nucleares específicos, como por exemplo o tipo CANDU [5,47]. Esse radioisótopo possui uma meia-vida de 5,3 anos e no seu decaimento emite dois raios gama com energias de $1,17 \mathrm{MeV}$ e $1,33 \mathrm{MeV}$. 
Os raios-X são produzidos quando elétrons, obtidos por efeito termiônico em um filamento aquecido, são acelerados por uma diferença de potencial incidindo sobre um alvo de material pesado. O desvio na trajetória dos elétrons provocado pelo impacto com o alvo gera os raios-X e esse fenômeno é conhecido como bremsstrahlung, Figura 2 (a). É igualmente denominada raio-X (ou raio-X característico) a energia emitida por um elétron ligado ao átomo quando este salta de uma órbita mais externa para uma órbita mais interna, Figura 2 (b).

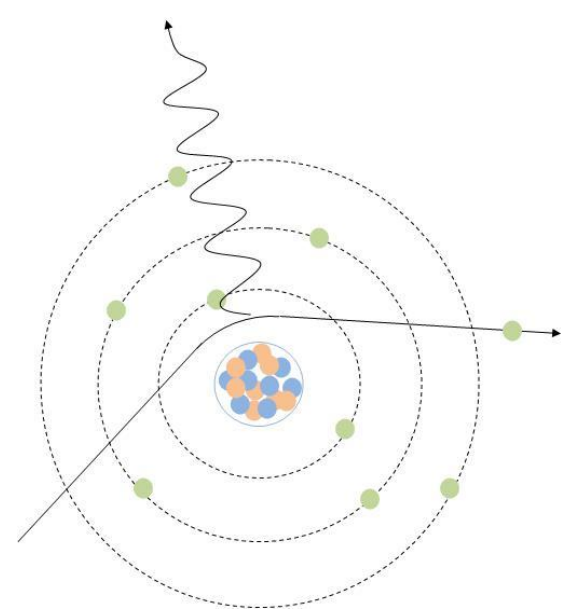

(a)

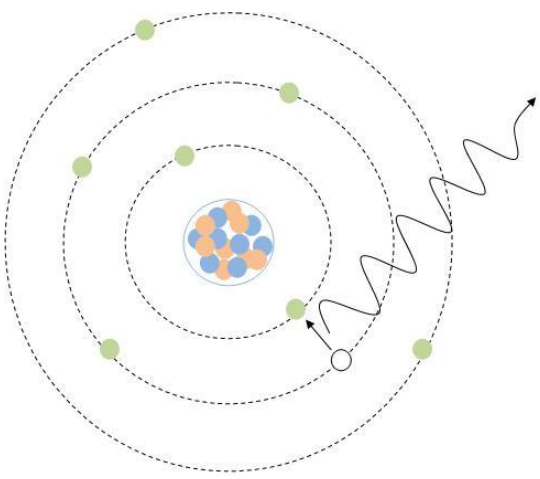

(b)

Figura 2 - Representação esquemática da emissão de raio-X: (a) Bremsstrahlung e (b) raio-X característico.

Os feixes de elétrons para processamento industrial são gerados em aceleradores; como exemplo onde se estabelece uma diferença de potencial de milhões de Volts entre o filamento e o ânodo em um tubo com vácuo. Os elétrons são obtidos no filamento e acelerados em direção ao ânodo incidindo diretamente no material processado após atravessarem uma janela de tungstênio. Também existem aceleradores de elétrons com outras características construtivas, como os aceleradores Linacs, onde os elétrons são injetados em um guia de onda (ou cavidade ressonante) preenchido com campos que variam em fase com o deslocamento dos elétrons, acelerando-os [1]. 


\subsubsection{Reações fotoquímicas}

A transferência de energia das radiações no processamento industrial ocorre por meio de interações com os elétrons orbitais do material processado, provocando excitação e ionização dos átomos e moléculas que formam o material.

\subsubsection{Excitação}

A excitação ocorre quando o elétron é deslocado da sua órbita de equilíbrio para uma órbita com maior energia de ligação e ao retornar emite o excesso de energia na forma de luz ou raio-X característico.

Em princípio, radiações eletromagnéticas de qualquer energia podem iniciar reações fotoquímicas. Fótons de baixa energia podem iniciar reações químicas que são indistinguíveis das reações iniciadas por movimento térmico à temperatura ambiente. A fotossíntese de plantas, por exemplo, é iniciada por fótons com $\mathrm{E}=1,82 \mathrm{eV}$, que é radiação eletromagnética de baixa energia e ainda não é ionizante [2].

\subsubsection{Ionização}

A ionização ocorre quando um elétron é removido da orbita atômica, resultando em um elétron livre de alta energia e um íon positivo, ou um radical livre quando ocorre uma quebra de ligação química.

Os fótons podem quebrar ligações químicas das moléculas, incluindo o DNA. O potencial de ionização de moléculas orgânicas dos alimentos normalmente está entre 6 e 12 $\mathrm{eV}$, e fótons com as energias encontradas em irradiadores industriais podem ionizar essas moléculas [2].

Energias na região do ultravioleta, por exemplo, já podem ser utilizadas para iniciar reações químicas acelerando o processo de cura de tintas ou até mesmo serem utilizadas como germicida em situações específicas [2]. 


\subsubsection{Interação de raios gama e raios-X com a matéria}

Os raios gama e os raios-X diferem somente na maneira como são produzidos e as interações deles com a matéria são idênticas e ocorrem principalmente por efeito fotoelétrico, efeito Compton e produção de pares [44-46].

Os raios-X e gama podem extrair elétrons dos átomos. Esses elétrons rápidos são responsáveis pela maioria das excitações e ionizações que provocam os efeitos químicos e biológicos, não importando se são originados por raios-X, gama ou aceleradores de elétrons [2].

\subsubsection{Efeito fotoelétrico}

No efeito fotoelétrico, Figura 3, é observada a transferência total da energia da radiação incidente para um elétron ligado (fotoelétron), que é ejetado do átomo com energia cinética $\mathrm{E}_{\mathrm{c}}$ dada por

$$
\mathrm{E}_{\mathrm{c}}=\mathrm{E}_{\gamma}-\mathrm{E}_{\mathrm{L}}
$$

onde $\mathrm{E}_{\mathrm{c}}$ é a energia cinética do elétron, $\mathrm{E}_{\gamma}$ é a energia do fóton incidente e $\mathrm{E}_{\mathrm{L}}$ é a energia de ligação do elétron.

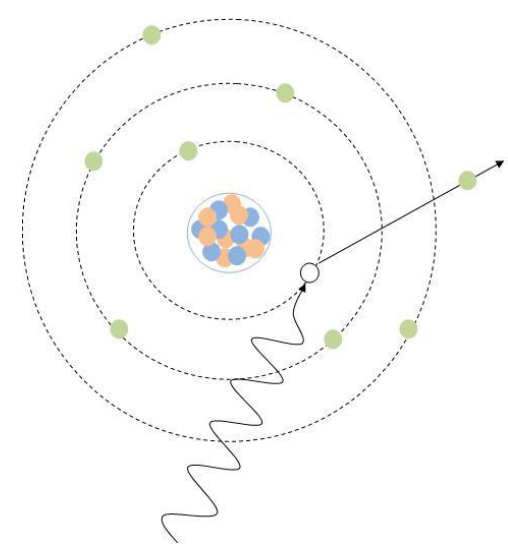

Figura 3 - Representação esquemática do efeito fotoelétrico. 
O efeito fotoelétrico cria um átomo ionizado com a falta do elétron ejetado. Essa vacância é rapidamente preenchida após o rearranjo dos elétrons orbitais, seguida da emissão de um fóton chamado raio-X característico.

A interação acontece com o átomo como um todo, portanto não ocorre com elétrons livres. Para fótons com energias adequadas a esse tipo de interação, o fotoelétron mais provável é o mais ligado ao átomo, presentes nas camadas $\mathrm{K}$ ou $\mathrm{L}$.

Esse efeito é predominante para baixas energias e para elementos químicos de elevado número atômico $(\mathrm{Z})$. A probabilidade de sua ocorrência aumenta com $\mathrm{Z}$ e decresce rapidamente com a energia.

\subsubsection{Efeito Compton}

No efeito Compton, Figura 4, somente uma fração da energia do fóton incidente é transferida para um elétron dos orbitais mais externos do átomo, considerado em repouso para a interação e que é ejetado com uma determinada quantidade de energia cinética (chamado elétron de recuo), enquanto o restante da energia é carregado pelo fóton espalhado em outra direção, formando um angulo $\theta$ com a direção de incidência. Como todos os ângulos de espalhamento são possíveis, a energia do elétron pode variar de zero a um valor máximo.

Figura 4 - Representação esquemática do efeito Compton. 
A expressão que relaciona a energia transferida e o ângulo de espalhamento pode ser obtida escrevendo simultaneamente as equações de conservação de energia e momento:

$$
E_{e}=\frac{E_{i}}{1+\frac{E_{i}}{m_{0} c^{2}}(1-\cos \theta)}
$$

onde $\mathrm{E}_{\mathrm{e}}$ é a energia do fóton espalhado, $\mathrm{E}_{\mathrm{i}}$ é a energia do fóton incidente e $\mathrm{m}_{0} \mathrm{c}^{2}$ é a massa de repouso do elétron $(511 \mathrm{keV})$.

A probabilidade do espalhamento depende da quantidade de elétrons disponíveis no material e cresce linearmente com Z .

\subsubsection{Produção de pares}

A produção de pares, Figura 5, ocorre quando um fóton com energia maior que duas vezes a massa de repouso de um elétron $\left(2 \mathrm{~m}_{0} \mathrm{c}^{2}=1,022 \mathrm{MeV}\right)$ interage com o campo coulombiano do núcleo atômico, desaparecendo e dando origem a um par elétron-pósitron. A energia excedente do fóton é convertida em energia cinética e divida entre as partículas.

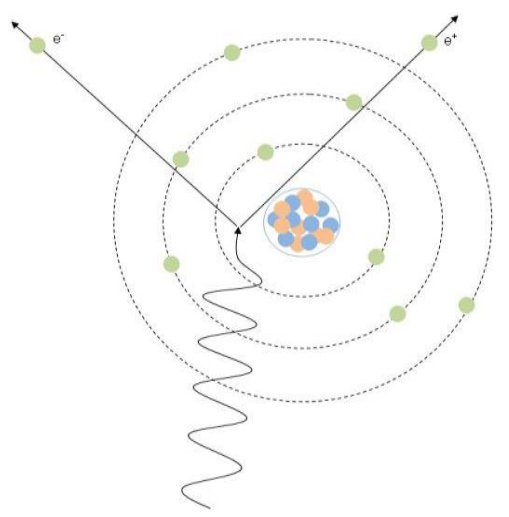

Figura 5 - Representação esquemática da produção do par elétron-pósitron. 
Após perder sua energia cinética no meio, o pósitron é aniquilado ao encontrar um elétron, originando um par de fótons diametralmente opostos com energia de $511 \mathrm{keV}$ cada.

Na Figura 6 pode-se observar a predominância de cada efeito em função da energia do fóton incidente e do número atômico do material absorvedor. No processamento industrial por radiação com o radioisótopo Co-60 $(\mathrm{E} \gamma=1,17$ e 1,33 MeV) pode ser verificada a predominância do efeito Compton.

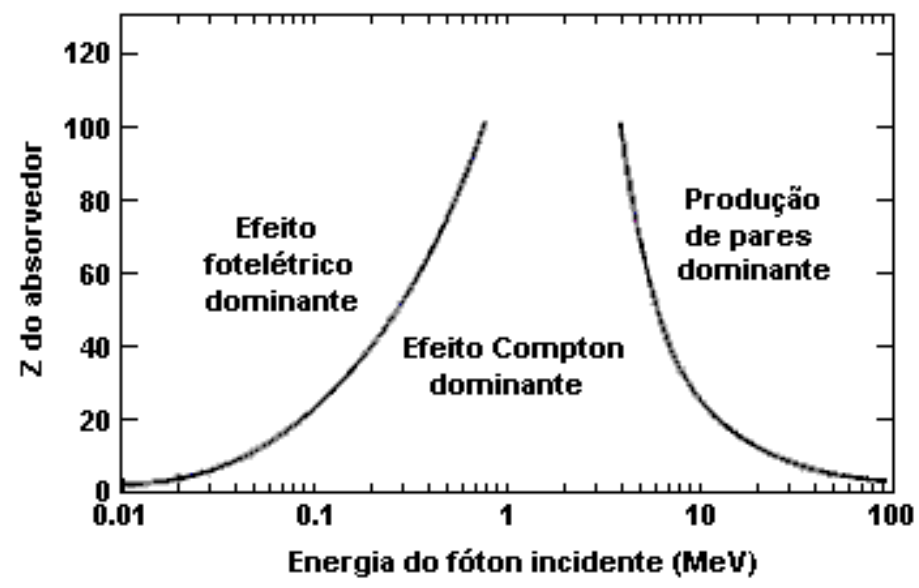

Figura 6 - Distribuição da predominância de cada um dos três principais meios de interação dos fótons com a matéria [46].

\subsection{Formação e recombinação do ozônio}

$\mathrm{O} \mathrm{O}_{3}$ é um agente oxidante muito forte e encontra algumas aplicações em processos como tratamento de água, tratamento de efluentes industriais e preservação de alimentos, atuando sozinho ou combinado com ultrassom, radiação ultravioleta ou com feixe de elétrons [48-52].

No meio ambiente o $\mathrm{O}_{3}$ é um dos poluentes mais agressivos, sendo considerado pela resolução CONAMA n 03/90 um poluente primário, afetando diretamente a saúde da população e secundário, afetando a fauna, flora, materiais e o meio ambiente em geral [27]. 


\subsubsection{Formação do ozônio}

Basicamente a formação do $\mathrm{O}_{3}$ ocorre por meio da dissociação das moléculas de $\mathrm{O}_{2}$ em radicais excitados $\mathrm{O}^{*}$, que se recombinam com outras moléculas de $\mathrm{O}_{2}$ formando o $\mathrm{O}_{3}$. Esse mecanismo de dissociação pode ocorrer pela interação com elétrons rápidos ou com radiação eletromagnética (raios-X e gama) e ainda por contribuição da presença de outro poluente, como o $\mathrm{NO}_{2}[20,25,48]$ :

a) processo de formação de $\mathrm{O}_{3}$ por elétrons rápidos

$\mathrm{e}^{-}+\mathrm{O}_{2} \rightarrow 2 \mathrm{O}^{*}+\mathrm{e}^{-}$

$\mathrm{O}^{*}+\mathrm{O}_{2}+\mathrm{M} \rightarrow \mathrm{O}_{3}+\mathrm{M}^{*}$, onde $\mathrm{M}$ representa uma molécula de um gás inerte, por exemplo $\mathrm{N}_{2}$, que remove o excesso de energia adquirido pelo $\mathrm{O}_{3}$ imediatamente ao encontro molecular.

b) processo de formação de $\mathrm{O}_{3}$ por radiação eletromagnética

$\mathrm{O}_{2}+\mathrm{hc} / \lambda \rightarrow 2 \mathrm{O}^{*}$

$\mathrm{O}^{*}+\mathrm{O}_{2} \rightarrow \mathrm{O}_{3}$, onde hc/ $\lambda$ é a energia o fóton incidente, sendo $\mathrm{h}$ a constante de Planck, c a velocidade da luz no vácuo e $\lambda$ o comprimento de onda do fóton que neste caso deve ser menor que $242 \mathrm{~nm}$.

c) contribuição do $\mathrm{NO}_{2}$ na formação do $\mathrm{O}_{3}$

$\mathrm{NO}_{2}+\mathrm{hc} / \lambda \rightarrow \mathrm{O}^{*}+\mathrm{NO}^{*}$

$\mathrm{O}^{*}+\mathrm{O}_{2} \rightarrow \mathrm{O}_{3}, \operatorname{com} \lambda<380 \mathrm{~nm}$.

$\mathrm{Na}$ literatura, o rendimento químico na formação de moléculas para certa energia depositada no meio é expresso pelo valor $G$, onde $G=n^{\circ} X$ de moléculas formadas/E, sendo E a energia expressa em unidades de $100 \mathrm{eV}$. Admitindo que a produção de $\mathrm{O}_{3}$ esteja ocorrendo por qualquer um dos processos acima, para o caso específico do $\mathrm{O}_{3}$ sendo formado pela interação da radiação gama com o $\mathrm{O}_{2}, \mathrm{G}$ está entre 9 e 13 moléculas/100 eV [34]. 


\subsubsection{Recombinação do ozônio}

Como a molécula de $\mathrm{O}_{3}$ é um forte oxidante, ela pode se recombinar com vários materiais bastando apenas ter elétrons disponíveis para a reação química. Porém, simultaneamente à produção de $\mathrm{O}_{3}$, existem mecanismos de decomposição com os mesmos reagentes e produtos $[20,25,48]$ :

$\mathrm{e}^{-}+\mathrm{O}_{3} \rightarrow \mathrm{O}_{2}+\mathrm{O}^{*}+\mathrm{e}^{-}$

$\mathrm{O}^{*}+\mathrm{O}_{3} \rightarrow 2 \mathrm{O}_{2}$

$\mathrm{O}_{3}+\mathrm{hc} / \lambda \rightarrow \mathrm{O}^{*}+\mathrm{O}_{2}, \operatorname{com} 200<\lambda<308 \mathrm{~nm}$

$\mathrm{O}_{3}+\mathrm{NO}^{*} \rightarrow \mathrm{NO}_{2}+\mathrm{O}_{2}$

\subsection{Irradiadores industriais de grande porte}

Como este trabalho estuda a produção de ozônio em irradiadores com cobalto 60 , para descrição deste tipo de equipamento utilizou-se a classificação da Agência Internacional de Energia Atômica (AIEA) que divide tais equipamentos que utilizam fontes de radiação gama em quatro categorias [53].

$\mathrm{Na}$ categoria I são classificados os irradiadores que possuem a fonte permanentemente blindada (auto-blindado) em um container seco onde é fisicamente impossível ter acesso ao campo de radiação ou à fonte radiativa sem ser através do tubo de transporte exclusivo para este fim. Apresentam pequeno volume na câmara de irradiação e, como esta é fechada, apresentam produção de $\mathrm{O}_{3}$ desprezível. A Figura 7 apresenta um exemplo de irradiador de categoria I. 


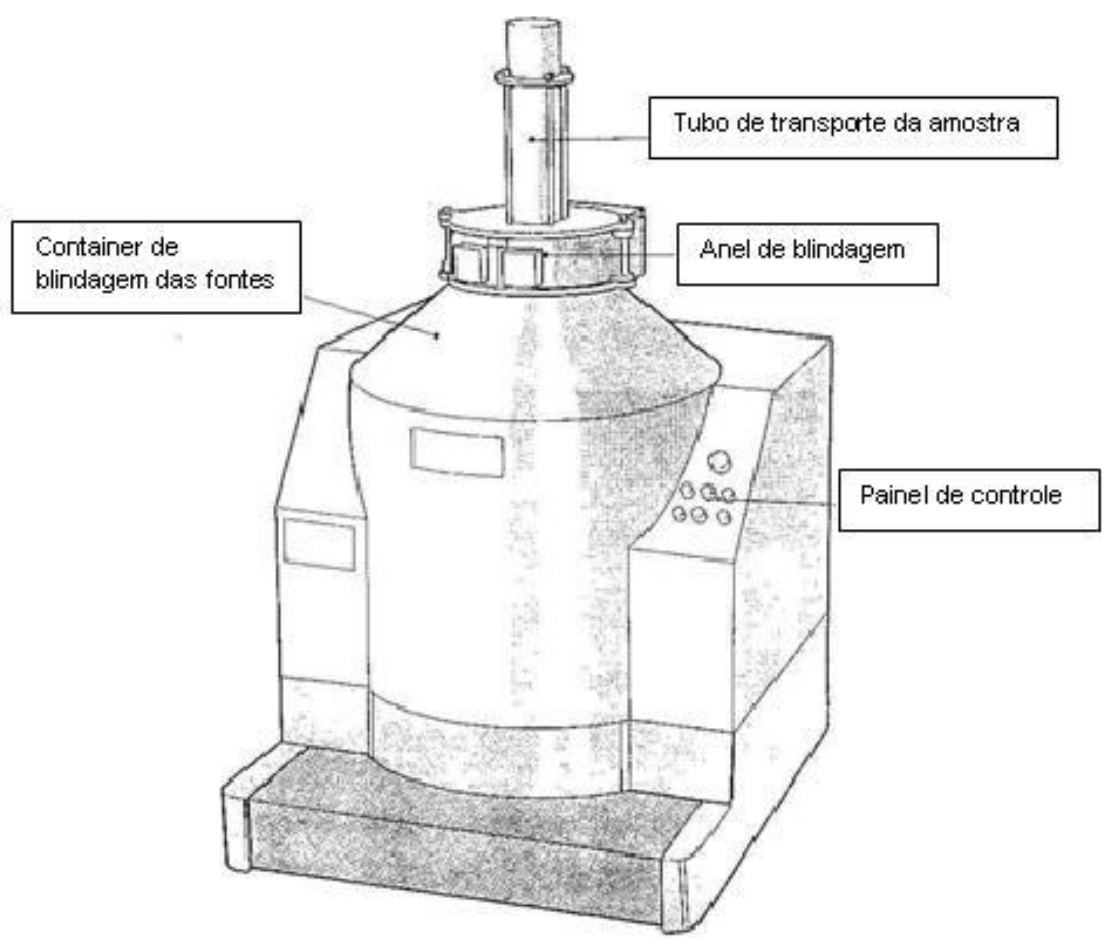

Figura 7 - Esquema de um irradiador gama categoria I pela AIEA [54].

Na categoria II são classificados os irradiadores que possuem a fonte radioativa completamente blindada em um container construído para este fim, enquanto o equipamento não estiver em uso. Quando em uso, a fonte é retirada do container por meio de um sistema mecânico apropriado e a sala de irradiação é mantida fechada por meio de sistema de intertravamento e segurança. Tais equipamentos são normalmente denominados irradiadores do tipo panorâmico. Nesse tipo de irradiador o volume irradiado é o volume da câmara de irradiação da instalação e nesta situação a produção de $\mathrm{O}_{3}$ já não é desprezível. A Figura 8 apresenta um exemplo de irradiador da categoria II. 


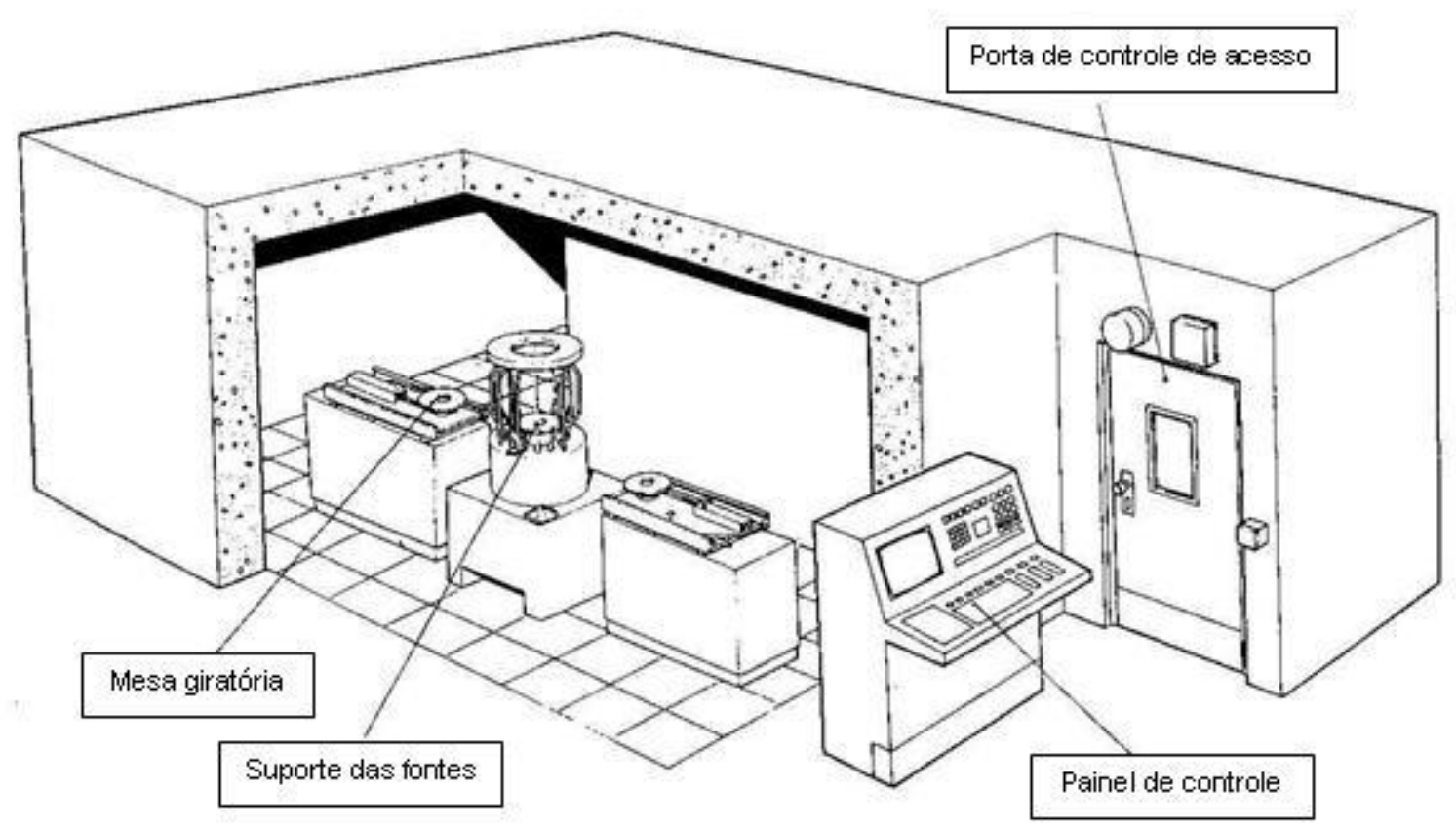

Figura 8 - Esquema de um irradiador gama panorâmico categoria II pela AIEA [53].

$\mathrm{Na}$ categoria III são classificados os irradiadores onde a fonte radiativa é permanentemente estocada em uma piscina com água que também oferece a função de blindagem para a radiação. Nesse tipo de irradiador o acesso à fonte ou ao campo de radiação é fisicamente restrito devido às características construtivas do equipamento. No processo de irradiação, a amostra deve ser levada até o campo de radiação ou a fonte por um sistema mecânico apropriado. Nessa categoria, como não há exposição de ar à fonte radioativa, a produção de $\mathrm{O}_{3}$ pode ser considerada inexistente. A Figura 9 apresenta um esquema com um irradiador da categoria III. 


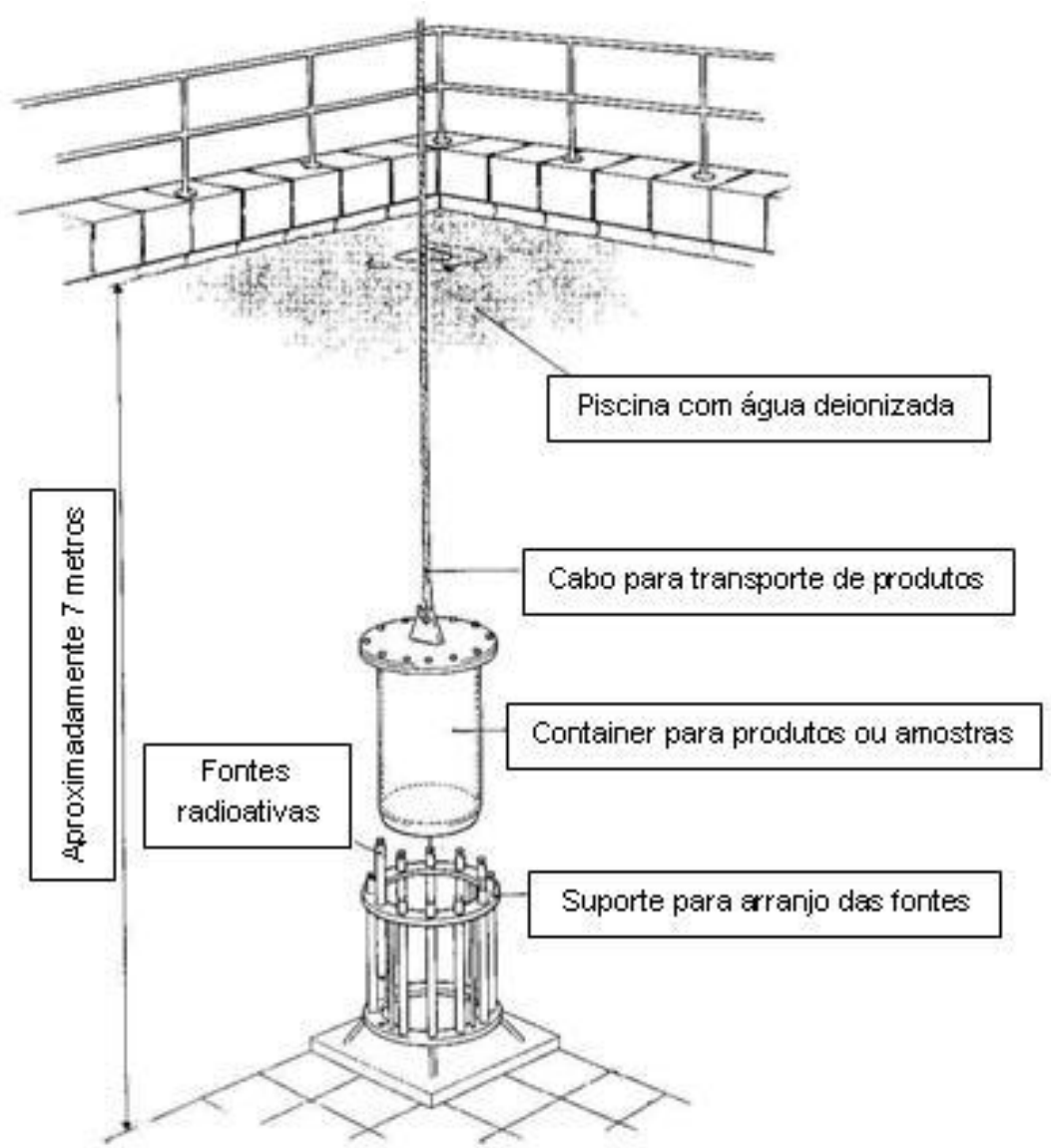

Figura 9 - Esquema de um irradiador gama categoria III pela AIEA [53].

$\mathrm{Na}$ categoria IV são classificados os irradiadores onde a fonte radiativa é permanentemente estocada em uma piscina com água que também oferece a função de blindagem para a radiação. Porém, diferentemente dos equipamentos categoria III, nesse tipo de irradiador as fontes ficam armazenadas no fundo da piscina quando o equipamento está fora de uso e são suspensas para a câmara de irradiação, por meio de um sistema mecânico apropriado, durante a irradiação de produtos. Durante o processamento por radiação, a câmara de irradiação fica fechada por meio de sistemas de intertravamento e segurança. Como os irradiadores da categoria II, o volume irradiado é o volume da câmara e consequentemente a produção de $\mathrm{O}_{3}$ também não é desprezível. A Figura 10 apresenta um exemplo de irradiador de categoria IV. 


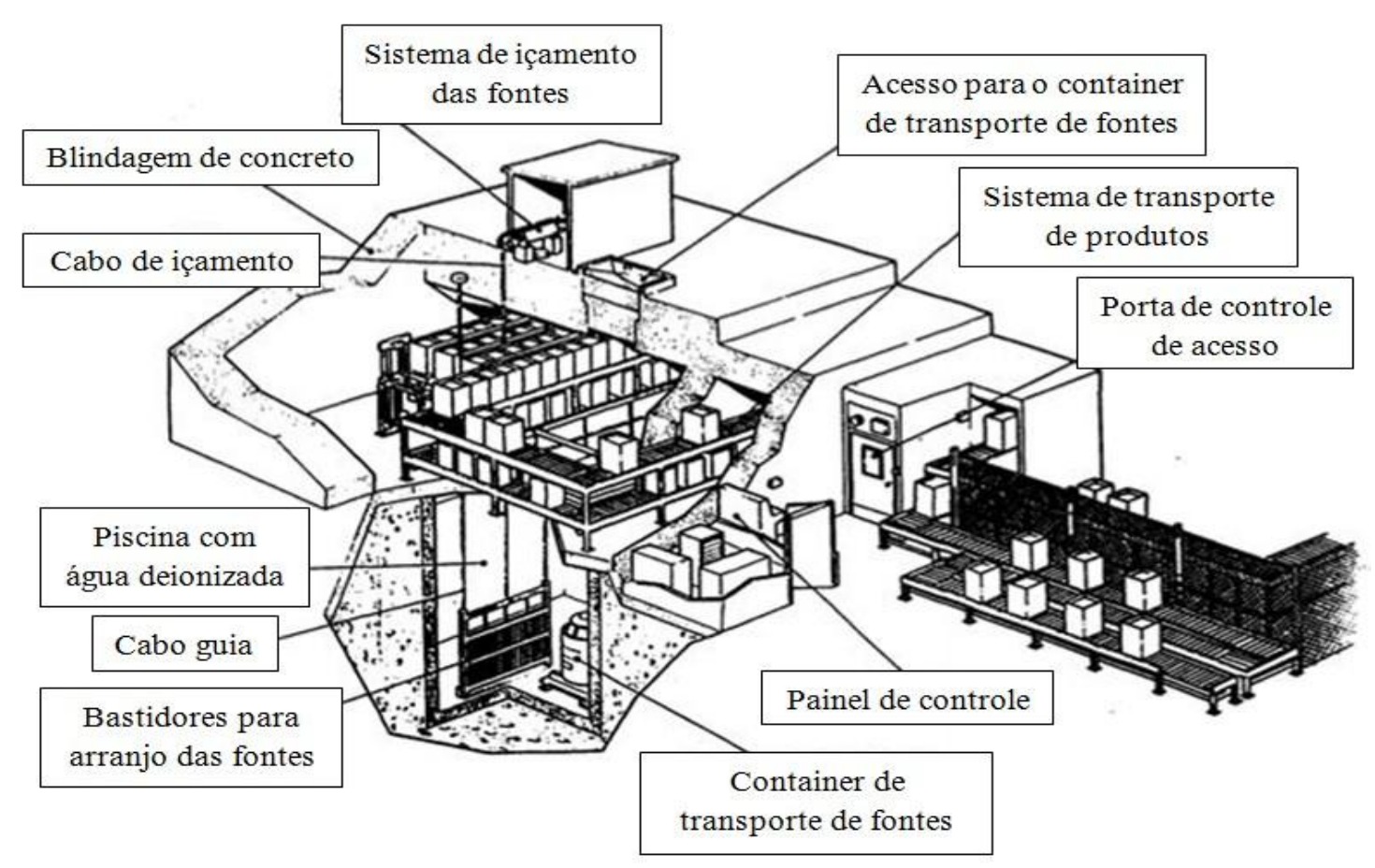

Figura 10 - Esquema de um irradiador gama categoria IV pela AIEA [53].

Para a Comissão Nacional de Energia Nuclear (CNEN) os irradiadores gama estão classificados em: Grupo I para instalações de grande porte que utilizam fontes seladas em processos industriais induzidos por radiação e Grupo 2, Subgrupo 2A para instalações que utilizam fontes seladas em equipamentos de grande porte autoblindados, que não permitem o acesso às fontes nem à câmara de irradiação, e nos quais não há deslocamento das fontes em operação rotineira [55].

$\mathrm{Na}$ elaboração deste trabalho, foram efetuadas medidas no Irradiador Multipropósito de Co-60 tipo compacto do Instituto de Pesquisas Energéticas e Nucleares (IPEN/CNEN-SP), Figura 11, e em mais três irradiadores comerciais no estado de São Paulo, todos classificados como grupo I pela CNEN e categoria IV pela IAEA. 


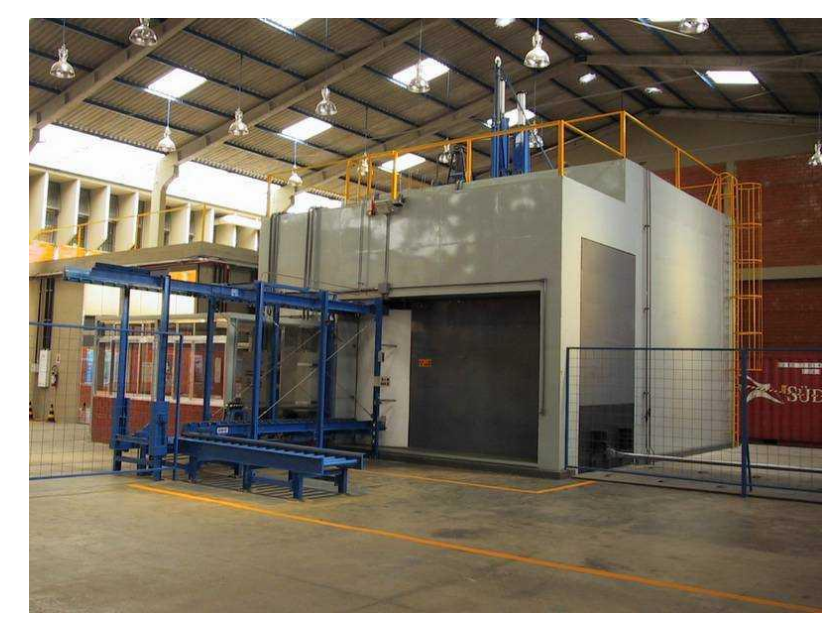

Figura 11 - Foto do irradiador multipropósito de Co-60 tipo compacto do IPEN/CNEN-SP.

O irradiador multipropósito do IPEN/CNEN-SP possui dois modos de operação, estático e dinâmico: no modo estático os produtos são acondicionados na câmara de irradiação e após certo tempo o processamento é interrompido pelo operador que reposiciona os produtos, para melhorar a uniformidade da dose absorvida pelo produto irradiado e, finaliza o processo; no modo dinâmico os produtos são acondicionados em caixas de alumínio que são fixadas ao sistema de transporte e, tal sistema faz a entrada e saída de caixas no interior da câmara de irradiação passando por uma porta giratória sem interrupção do processamento.

A câmara de irradiação do irradiador do IPEN/CNEN-SP fica completamente fechada durante o processamento por conta da porta giratória, tal característica faz com que a entrada de ar externo para a câmara de irradiação ocorra apenas pelas frestas da porta giratória de produtos e da porta deslizante de serviço. A Figura 12 apresenta uma vista em corte do irradiador multipropósito do IPEN/CNEN-SP. 


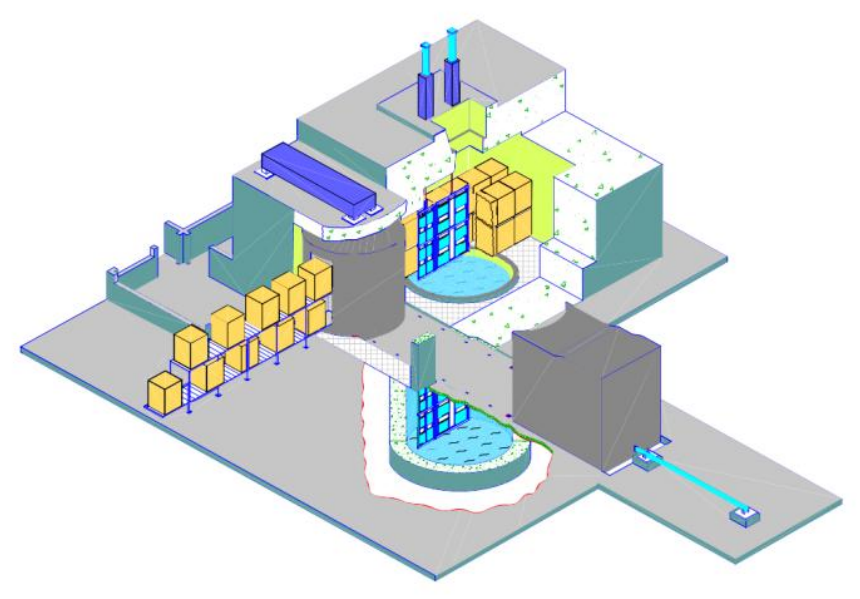

Figura 12 - Esquema em corte do Irradiador Multipropósito de Co-60 tipo compacto do IPEN/CNEN-SP [5].

Os demais irradiadores possuem labirintos com função de blindagem radiológica e durante a operação, as caixas com os produtos são fixadas ao sistema de transporte que leva as embalagens até a câmara de irradiação atravessando a porta de entrada e saída de produtos. A porta de produtos fica permanentemente aberta e um conjunto de grades, com função de proteção física, impede o acesso não autorizado ao interior do equipamento. Esta configuração permite o fluxo de ar para o interior da câmara de irradiação. 


\section{MATERIAIS E MÉTODOS}

\subsection{Equipamento de medição}

$\mathrm{O}$ equipamento utilizado para medir a concentração de $\mathrm{O}_{3}$ foi o monitor modelo 49 $\mathrm{C} \mathrm{O}_{3}$ Analyzer, fabricado pela empresa Thermo Environmental Instruments, fornecido pelo Centro de Química e Meio Ambiente do IPEN/CNEN-SP.

O monitor 49C tem o seu princípio de funcionamento baseado em absorção óptica, com um limite mínimo de detecção, segundo o fabricante, de 0,002 ppm. As moléculas de $\mathrm{O}_{3}$ absorvem luz ultravioleta no comprimento de onda de $254 \mathrm{~nm}$ e o monitor relaciona a concentração de $\mathrm{O}_{3}$ com a medida desta atenuação da luz por meio da lei de Beer-Lambert $[56,57]$ na equação:

$$
\frac{I}{I_{0}}=e^{-K L C}
$$

onde:

I = Intensidade da luz ultravioleta da amostra de gás;

$\mathrm{I}_{0}=$ Intensidade da luz ultravioleta da amostra de gás de referência (gás sem $\mathrm{O}_{3}$ );

$\mathrm{K}=$ Coeficiente de absorção, $308 \mathrm{~cm}^{-1}$ a $0{ }^{\circ} \mathrm{C}$ e 1 atmosfera;

$\mathrm{L}=$ Comprimento da câmara $(\mathrm{cm})$;

$\mathrm{C}=$ Concentração de $\mathrm{O}_{3}(\mathrm{ppm})$.

O monitor possui duas câmaras para a amostra de gás, uma para o gás de referência (gás sem $\mathrm{O}_{3}$ ) e outra para o gás a ser analisado. $\mathrm{O}$ gás é bombeado para as câmaras, com um fluxo de 1 a 3 l/min, passando primeiramente por um filtro de Teflon ${ }^{\circledR}$ para a retirada de material particulado. O gás de referência passa também por um conversor catalítico para a remoção de todo o $\mathrm{O}_{3}$. A cada 10 segundos, válvulas solenoides e bomba se alternam e 
purgam o gás de referência e o da amostra para o interior das câmaras. O monitor realiza as medidas e grava na memória a média desses valores a cada minuto [56], sendo por tanto, um monitor de leitura direta que apresenta os valores de concentração em tempo real. A Figura 13 mostra um desenho esquemático do funcionamento do monitor.

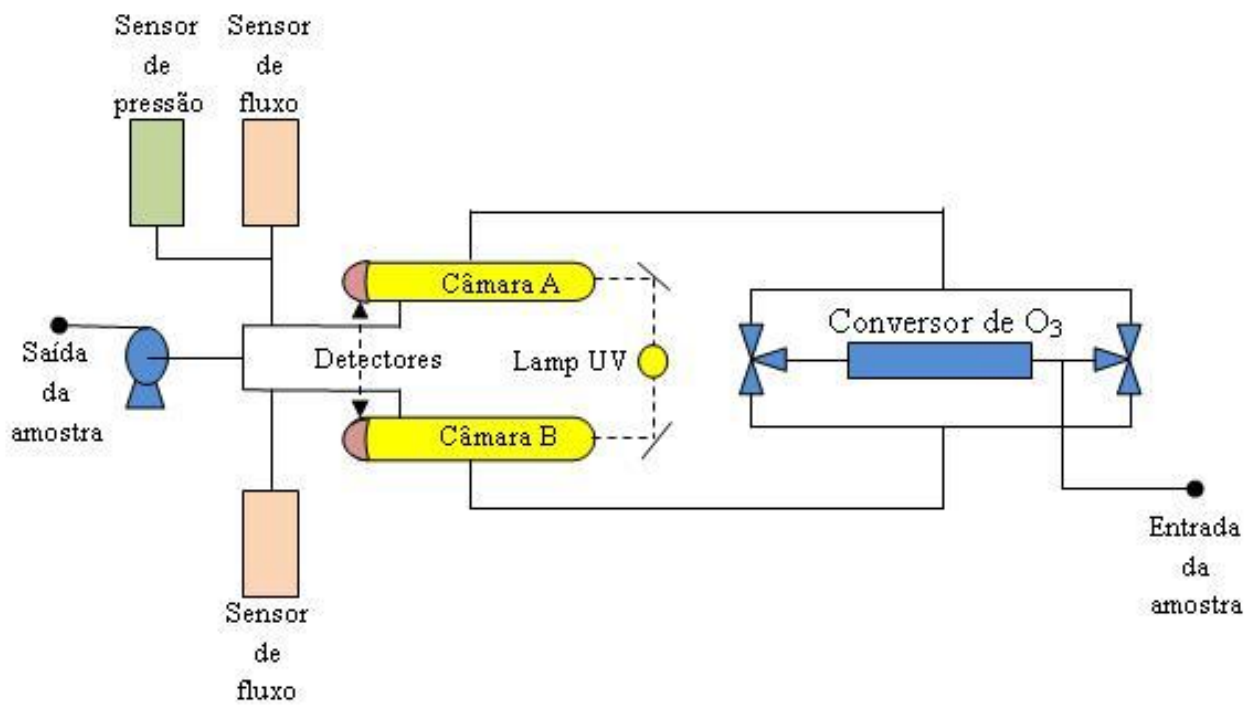

Figura 13 - Esquema de funcionamento do monitor 49C da Thermo Environmental Instruments. Figura modificada do catálogo técnico do fabricante [58].

O monitor possui uma saída serial na qual conecta-se um computador para acessar os valores das medidas e demais dados, tais como temperatura e pressão, e inclusive acompanhar as medidas por meio de gráficos de concentração x tempo utilizando um software próprio, TEI para sistema operacional Windows versão 2.2.

O monitor 49C possui dimensões de 430 x 220 x $580 \mathrm{~mm}$ e $16 \mathrm{~kg}$ e não é um equipamento portátil.

\subsection{Irradiadores e atividade em Co-60}

Com relação aos quatro irradiadores utilizados neste estudo, os valores de atividade das fontes de Co-60 disponíveis em cada instalação estão apresentados na Tabela 1. 
Tabela 1 - Valores de atividade em Co-60 disponível em cada instalação.

\begin{tabular}{c|c|c}
\hline Irradiador & Atividade total (PBq) & Data da atividade \\
\hline IPEN/CNEN-SP & 5,22 & $20 / 12 / 2012$ \\
\hline A & 95,14 & $23 / 07 / 2013$ \\
\hline B & 75,67 & $23 / 04 / 2013$ \\
\hline C & 32,61 & $23 / 04 / 2013$ \\
\hline
\end{tabular}

\subsection{Procedimentos para as medidas}

A coleta do gás a ser analisado ocorre por meio de uma mangueira de Teflon ${ }^{\circledR}$ com $4 \mathrm{~mm}$ de diâmetro e $6 \mathrm{~m}$ de comprimento, dentro dos limites de utilização para o equipamento segundo o fabricante, no qual uma extremidade é fixada na entrada de ar do equipamento passando pelo filtro para retenção de material particulado e a outra é fixada no ponto de coleta.

Os procedimentos para realização das medidas foram os seguintes:

1- Como procedimento padrão, sempre foi realizada uma medida da concentração de $\mathrm{O}_{3}$ presente no ambiente, a qual foi considerada como valor de fundo ou BG, background do inglês, e descontada das medidas realizadas na instalação, considerando suas respectivas incertezas.

2- Com o objetivo de verificar se ocorria alguma perda por inserção da mangueira no comprimento utilizado foram realizadas medidas comparativas com uma mangueira de $3 \mathrm{~m}$ e com uma de $15 \mathrm{~m}$, coletando amostras no sistema de exaustão do Irradiador Multipropósito do IPEN/CNEN-SP, em condições normais de operação (fonte exposta e exaustor ligado).

3- Foram realizadas medidas da concentração de $\mathrm{O}_{3}$ com o tempo de irradiação, em cada instalação. Medidas essas coletadas a partir das tubulações de exaustão em condições normais de trabalho, ou seja, com os exaustores ligados.

4- Foram realizadas medidas do tempo de meia-vida do $\mathrm{O}_{3}$ no irradiador multipropósito do IPEN/CNEN-SP, aguardando-se primeiramente a concentração de $\mathrm{O}_{3}$ atingir a região de equilíbrio com o exaustor desligado e após o recolhimento das fontes. 
As amostras foram coletadas no nível do piso interno do irradiador e, com diferentes volumes e produtos sendo irradiados. Essas medidas foram realizadas apenas no Irradiador Multipropósito do IPEN/CNEN-SP devido às dificuldades operacionais encontradas nos irradiadores comerciais.

5- Foram realizadas medidas das curvas do decaimento da concentração de $\mathrm{O}_{3}$, em cada instalação, medidos após o recolhimento das fontes de Co-60 com os dados coletados a partir das tubulações de exaustão em condições normais de trabalho.

6- Foram realizadas medidas da concentração de $\mathrm{O}_{3}$ a partir do ponto de exaustão para a atmosfera, na instalação com maior atividade em Co-60 disponível, a diferentes distâncias.

7- Foram realizadas medidas de concentração de $\mathrm{O}_{3}$ ao longo do diâmetro interno da tubulação de exaustão no irradiador multipropósito do IPEN/CNEN-SP.

8- Foram realizadas medidas de concentração de $\mathrm{O}_{3}$ ao longo da tubulação de exaustão no Irradiador Multipropósito do IPEN/CNEN-SP. 


\section{RESULTADOS E DISCUSSÃO}

\subsection{Concentração de $\mathrm{O}_{3}$ no ambiente}

A concentração de $\mathrm{O}_{3}$ no ambiente varia muito ao longo do dia, atingindo picos após os momentos de maior incidência de radiação solar [20]. Por esse motivo, os valores para o BG foram obtidos em intervalos de tempo da ordem de 15 a 30 minutos e, quando isso não foi possível, o valor de BG era medido no início e fim de cada ensaio. Não foram realizadas medidas no período noturno por não haver uma melhora na qualidade das medidas, pois também existem picos de concentração de $\mathrm{O}_{3}$ nesse período, que, segundo Pretto [20], está associada a um processo convectivo de transporte vertical que ocorre quando há passagens de frentes e jatos noturnos, e ainda, de acordo com Barcellos et al [59], o pico de concentração de $\mathrm{O}_{3}$ noturno está associado há reações envolvendo os poluentes $\mathrm{NO}_{2}$ e $\mathrm{NO}_{3}$, onde o $\mathrm{NO}_{2}{ }^{*}$ perde energia por luminescência emitindo um fóton $\operatorname{com} \lambda>400 \mathrm{~nm}$, e este fóton é absorvido por $\mathrm{NO}_{3}{ }^{*}$ na reação:

$\mathrm{NO}_{3}{ }^{*}+\mathrm{hc} / \lambda \rightarrow \mathrm{NO}_{2}{ }^{*}+\mathrm{O}(600 \mathrm{~nm}<\lambda<700 \mathrm{~nm})$ produzindo $\mathrm{O}_{3}$ pela reação:

$\mathrm{O}+\mathrm{O}_{2}+\mathrm{M} \rightarrow \mathrm{O}_{3}+\mathrm{M}$

\subsection{A mangueira utilizada para a coleta do gás}

Com relação ao comprimento da mangueira utilizada para a coleta do gás, foram realizadas medidas na tubulação de exaustão com dois comprimentos diferentes de mangueira. Isso foi feito para verificar se havia alguma influência sobre as medidas realizadas pelo monitor 49C em função de uma possível variação de pressão na tubulação ou mesmo adsorção por parte da mangueira, para diferentes comprimentos utilizados. Na medida com a mangueira curta, com $3 \mathrm{~m}$ de comprimento, foi obtido o valor de concentração de $\mathrm{O}_{3}$ de 119,6 \pm 0,9 ppb e na medida com a mangueira longa, com $15 \mathrm{~m}$ de comprimento, foi obtido o valor de 120,5 $\pm 1,5 \mathrm{ppb}$. Como as medidas foram 
estatisticamente iguais, isso mostrou que o equipamento consegue se adequar a uma possível variação de pressão pelo comprimento da mangueira e que não houve adsorção do gás pela mangueira que poderia comprometer os resultados.

\subsection{Medidas em condições normais de operação}

Foram realizadas medidas da concentração de $\mathrm{O}_{3}$ com o tempo de irradiação em cada instalação em condições normais de operação e com a atividade máxima. A Figura 14 apresenta a evolução temporal dessas medidas, pela qual se pode inferir que os sistemas tendem a apresentar uma região de equilíbrio na concentração de $\mathrm{O}_{3}$.

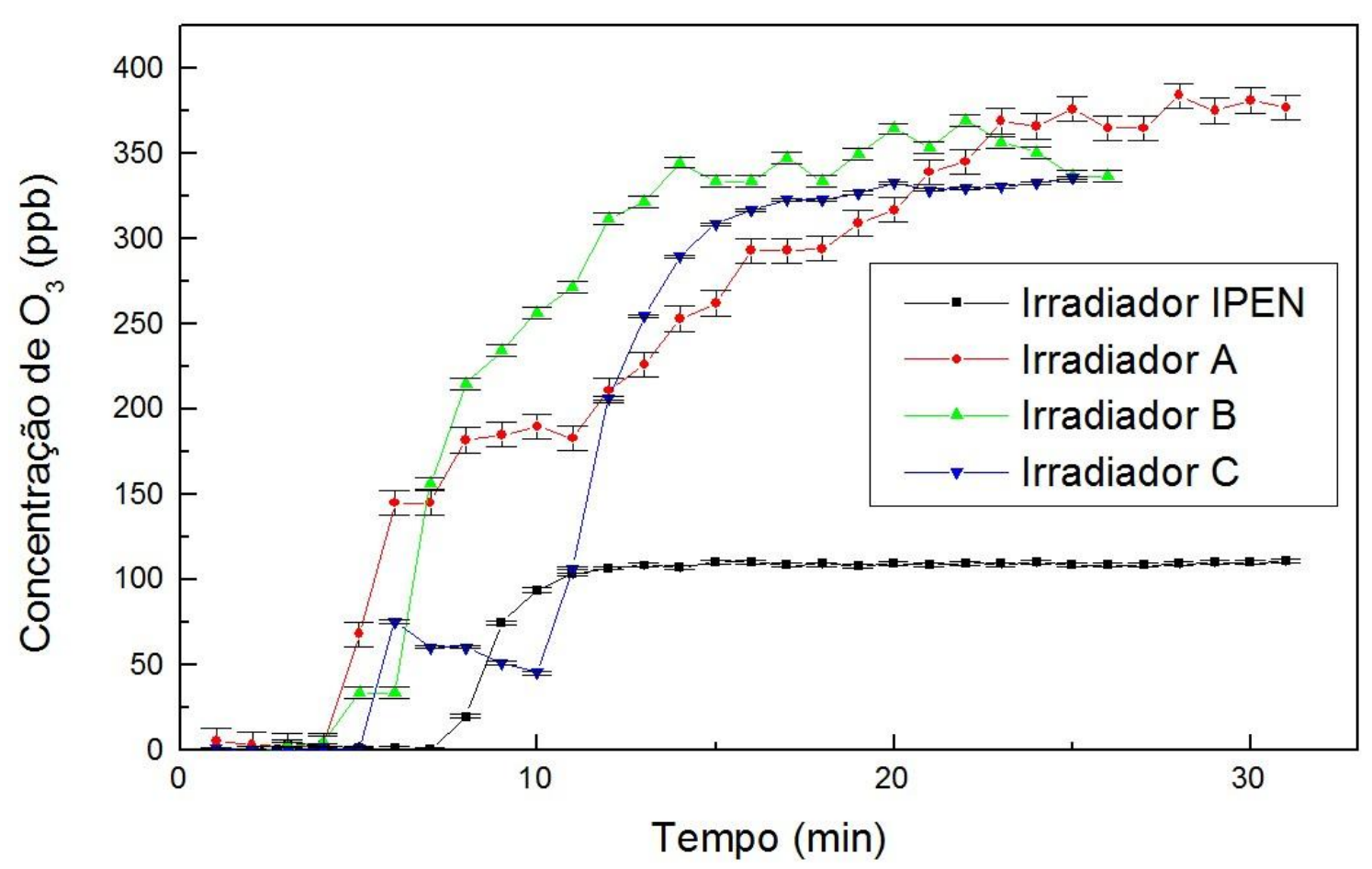

Figura 14 - Medidas tomadas nas tubulações de exaustão até a condição de equilíbrio.

A Tabela 2 apresenta os valores médios obtidos para essas regiões de equilíbrio em cada instalação, sendo que, para o Irradiador Multipropósito do IPEN/CNEN-SP, foi 
possível obter três valores de concentração em equilíbrio, uma vez que o equipamento possui dois bastidores de fontes independentes com atividades de $0,87 \mathrm{PBq}$ no bastidor $1 \mathrm{e}$ 4,35 $\mathrm{PBq}$ no bastidor 2, totalizando 5,22 $\mathrm{PBq}$ (valores de atividade obtidos em 20/12/2012).

Tabela 2 - Valores médios de concentração de equilíbrio de $\mathrm{O}_{3}$, obtidos nas tubulações de exaustão das instalações estudadas.

\begin{tabular}{c|c}
\hline Equipamento & Concentração (ppb) \\
\hline IPEN/CNEN-SP & $104 \pm 5$ (bastidor 1+2) \\
\hline IPEN/CNEN-SP & $83 \pm 2$ (bastidor 2) \\
\hline IPEN/CNEN-SP & $17 \pm 1$ (bastidor1) \\
\hline A & $357 \pm 27$ \\
\hline B & $338 \pm 18$ \\
\hline C & $281 \pm 7$
\end{tabular}

A partir dos valores médios da concentração de equilíbrio do $\mathrm{O}_{3}$ e das respectivas atividades em cada instalação foi construída a curva da Figura 15. Deve ser observado que apesar dos pontos de equilíbrio mostrarem uma concordância ao indicarem um ponto de saturação com a atividade, os pontos obtidos com os irradiadores testados são de situações diferentes, pois os equipamentos A, B e C permitem a entrada de ar continuamente e o Irradiador Multipropósito apenas pelas frestas. Apesar disso, existe uma concordância entre as curvas, que em trabalhos futuros poderão ser revistas, existindo a possibilidade da implementação de uma maior atividade no Irradiador Multipropósito do IPEN / CNEN-SP para verificação desse comportamento. Este comportamento está de acordo com Sears et al [32], que também observou uma condição de equilíbrio na produção de $\mathrm{O}_{3}$, e demonstrou que a taxa de produção não é linear para altas taxas de dose, pois a própria radiação incidente destrói as moléculas de $\mathrm{O}_{3}$, e reduz o rendimento da produção do gás. 


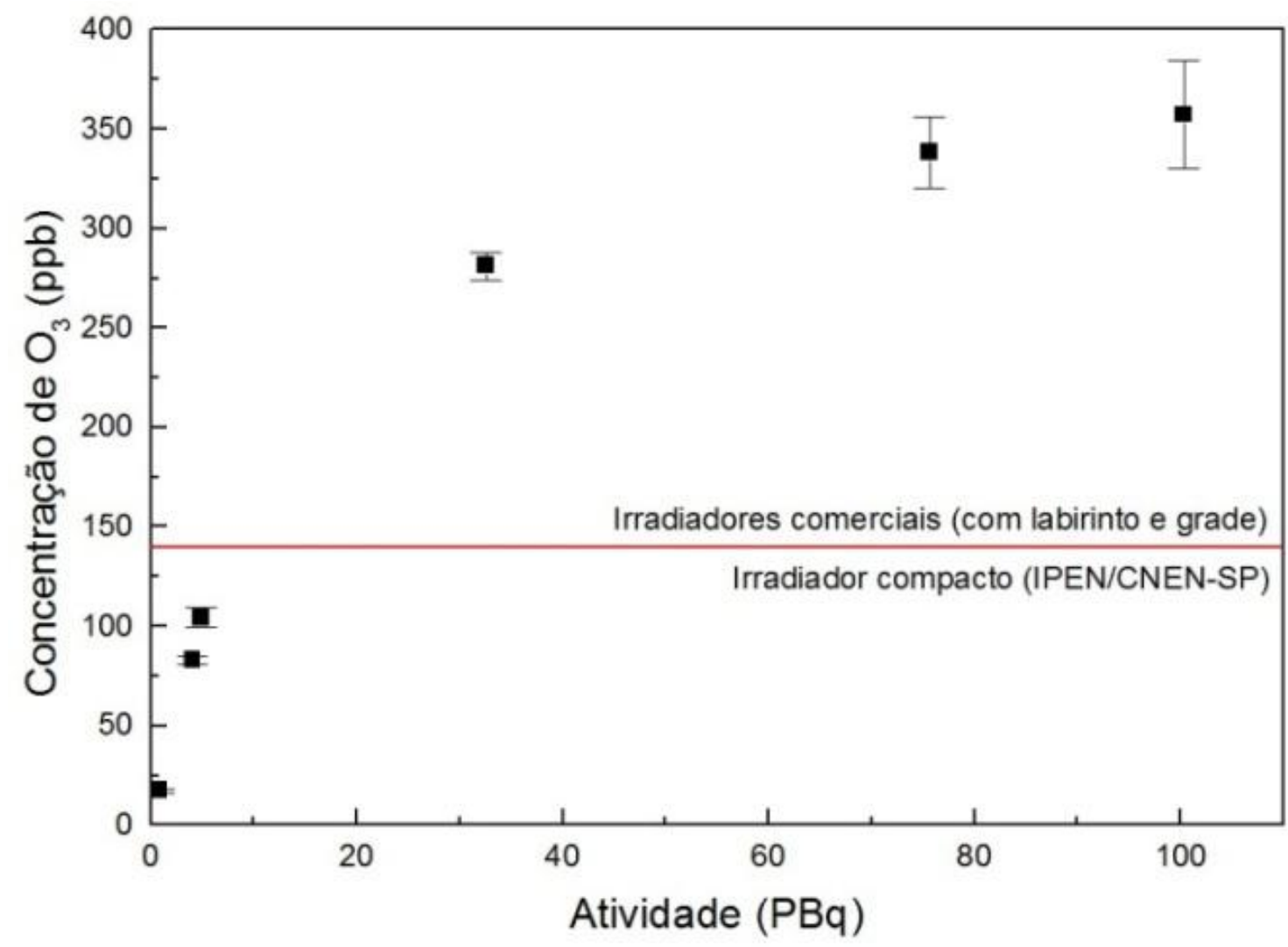

Figura 15 - Valores de concentração na condição de equilíbrio em função das atividades das fontes.

Considerando apenas as medidas realizadas no irradiador multipropósito do IPEN / CNEN - SP foi possível observar que houve uma linearidade entre a concentração de $\mathrm{O}_{3}$ na região de equilíbrio e as atividades disponíveis nessa instalação, conforme apresentado na Figura 16. 


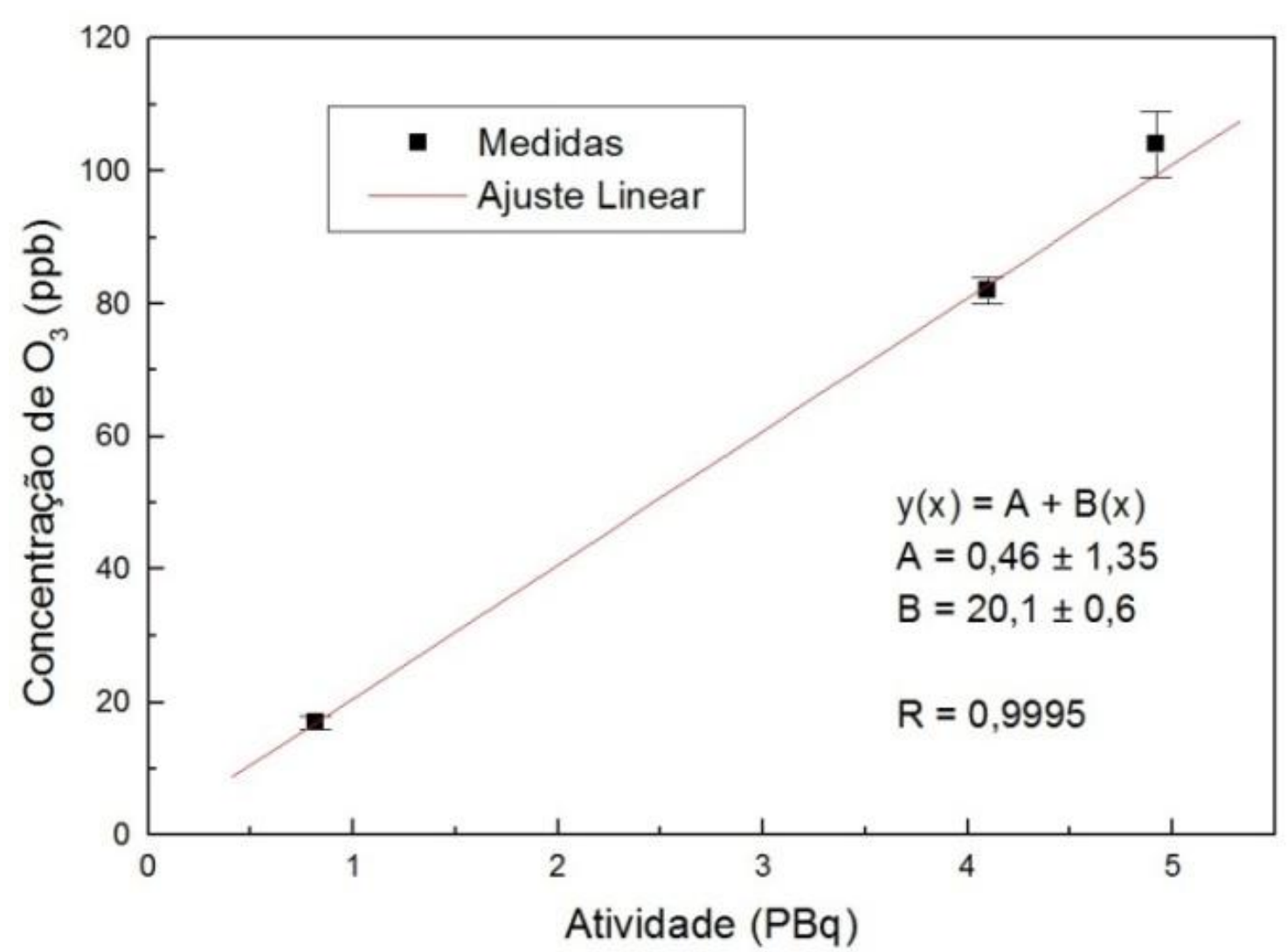

Figura 16 - Valores de concentração na condição de equilíbrio em função das atividades das fontes no Irradiador Multipropósito do IPEN / CNEN - SP.

\subsection{Medidas com o exaustor desligado}

No irradiador multipropósito do IPEN/CNEN-SP, com o sistema de exaustão desligado, com a máxima atividade disponível e após a concentração de $\mathrm{O}_{3}$ atingir a região de equilíbrio, foram medidos os tempos de meia-vida desse gás no interior da câmara de irradiação logo após o recolhimento das fontes, para diferentes volumes ocupados. As medições foram realizadas no nível do piso no interior da câmara de irradiação devido à tendência de precipitação deste gás e foi utilizado um circulador de ar no interior da câmara para uma melhor homogeneização. Na Figura 17 são apresentadas essas curvas de decaimento, juntamente com a curva para o irradiador vazio. Em termos de volume ocupado na câmara de irradiação temos: Vazio < V1 $\left(1,5 \mathrm{~m}^{3}\right.$ em embalagens de caixas de papelão) < V2 (2 m² em embalagens de caixas de papelão $)<$ V3 (3 m em embalagens de sacos de plástico). 
As diferenças nos valores máximos das concentrações de $\mathrm{O}_{3}$ já eram esperadas, pois à medida que a energia da radiação gama é depositada em algum produto, menos energia fica disponível para produzir reações no ar e esses valores tendem a se estabilizar em função de um volume mínimo livre que não pode ser ocupado por produtos e que permite a reação de produção de $\mathrm{O}_{3}$.

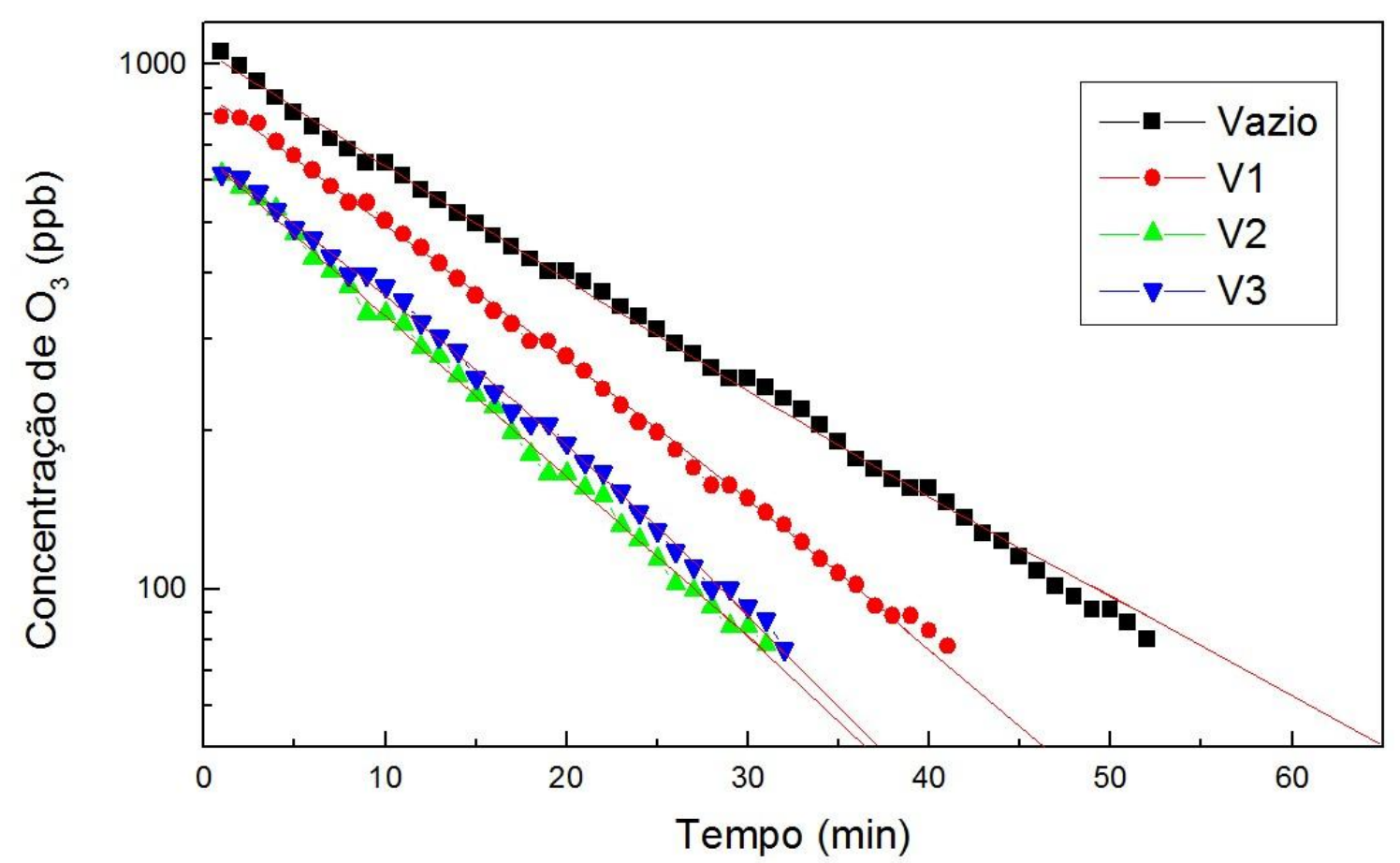

Figura 17 - Curvas de decaimento da concentração de $\mathrm{O}_{3}$ no nível do piso interno do Irradiador Multipropósito do IPEN/CNEN-SP para diferentes volumes ocupados e com a atividade máxima disponível na câmara de irradiação.

As curvas apresentadas na Figura 17, nesse caso, retas em escala logarítmica para os valores de concentração de $\mathrm{O}_{3}$, demonstram o comportamento exponencial de primeira ordem para o decaimento da concentração desse gás com o tempo, sendo assim, esta reação de decaimento pode ser dita como uma reação de primeira ordem na qual a velocidade de reação é proporcional a concentração do reagente, neste caso o $\mathrm{O}_{3}$ em processo de recombinação com o ar no interior da câmara de irradiação, com os elementos estruturais do equipamento e com as embalagens dos produtos. A extrapolação das curvas na Figura 17 indica o tempo que seria necessário para a concentração do gás ir a zero. Também é definido o tempo de meia-vida para uma substância neste tipo de reação como sendo o 
tempo necessário para sua concentração cair à metade do valor inicial [60]. Com esses dados foram calculados os tempos de meia-vida $\left(\mathrm{T}_{1 / 2}\right)$ para o decaimento da concentração do $\mathrm{O}_{3}$ para cada volume ocupado, resultados estes apresentados na Tabela 3.

Tabela 3 - Tempos de meia-vida para o decaimento do $\mathrm{O}_{3}$ no Irradiador Multipropósito do IPEN/CNEN-SP, para diferentes volumes ocupados.

\begin{tabular}{c|c|c}
\hline Volume & $\begin{array}{c}\text { Concentração } \\
\text { máxima }(\mathbf{p p b})\end{array}$ & $\mathbf{T}_{\mathbf{1 / 2}} \mathbf{( m i n )}$ \\
\hline Vazio & 1052 & $13,9 \pm 0,3$ \\
\hline V1 & 793 & $12,3 \pm 0,5$ \\
\hline V2 & 616 & $9,4 \pm 0,5$ \\
\hline V3 & 617 & $9,9 \pm 0,5$ \\
\hline
\end{tabular}

$\mathrm{O}$ decréscimo de $\mathrm{T}_{1 / 2}$ observado com o volume irradiado concordou com as observações citadas no "Technical Reports Series" n 188 publicado pela IAEA [41], a qual cita uma redução nos tempos de decaimento em função da reatividade desse gás com uma maior presença de produtos irradiados dentro da instalação. Considerando a média obtida a partir das quatro curvas apresentadas na Figura 17, o tempo de meia-vida do $\mathrm{O}_{3}$ para a instalação foi de $11,4 \pm 2,1 \mathrm{~min}$.

Ainda, a partir da curva de decaimento da concentração de $\mathrm{O}_{3}$, para a concentração máxima do gás obtida com a câmara vazia, destacada na Figura 18, que parte da concentração do gás em $1052 \pm 24$ ppb foi inferida a linearidade do equipamento analisador de $\mathrm{O}_{3}$ utilizado nas medições. 


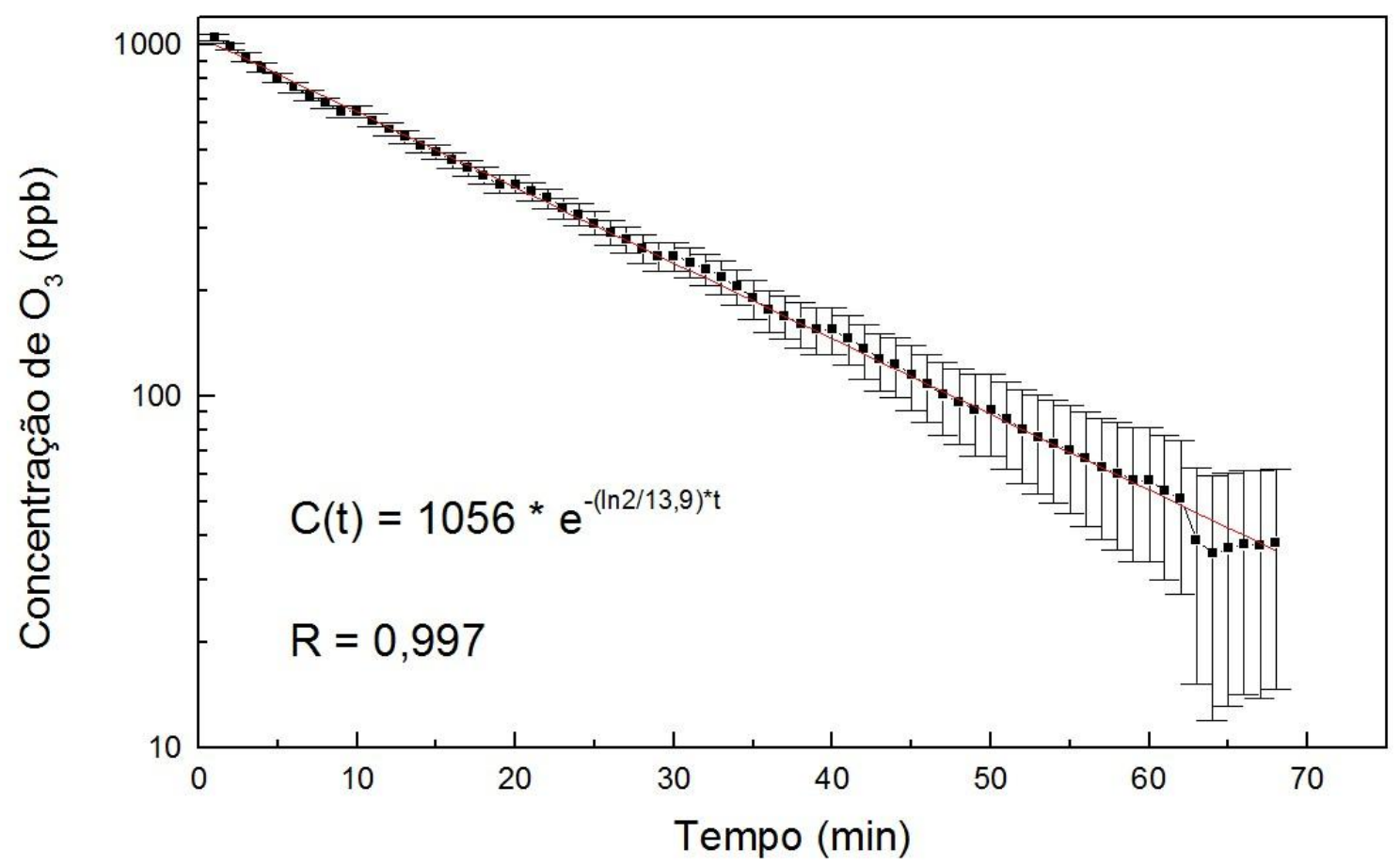

Figura 18 - Curva de decaimento da concentração de $\mathrm{O}_{3}$ no nível do piso interno do Irradiador Multipropósito do IPEN/CNEN-SP, com a câmara vazia.

A curva em vermelho é o ajuste com $\mathrm{R}=0,997$. Essa boa correlação da curva de decaimento do $\mathrm{O}_{3}$, desde 1050 ppb até 40 ppb, para uma equação exponencial de primeira ordem, além de assegurar a ordem da reação de decaimento do $\mathrm{O}_{3}$ na instalação estudada, atesta o correto funcionamento do detector de $\mathrm{O}_{3}$ utilizado, o $49 \mathrm{C} \mathrm{O}_{3}$ Analyzer, para esta faixa de concentrações de $\mathrm{O}_{3}$.

\subsubsection{Equações sugeridas}

Com auxílio da referência "Technical Reports Series" nº188 publicado pela IAEA [41], que é uma publicação sobre aspectos de proteção radiológica na operação de aceleradores lineares de elétrons, que propomos aplicar da mesma maneira para obtermos a concentração de $\mathrm{O}_{3}$ em irradiadores que utilizem radiação gama, devido à similaridade do fenômeno, podemos inferir que a concentração de $\mathrm{O}_{3}$ em função do tempo, $\mathrm{C}(\mathrm{t})$, pode ser obtida por meio da equação: 


$$
C(t)=\frac{p \bar{T}}{V}\left[1-e^{\frac{-t}{\bar{T}}}\right]
$$

na qual,

$\mathrm{t}=$ tempo de irradiação (min);

$\mathrm{p}=$ taxa de produção de $\mathrm{O}_{3}\left(\mathrm{ppb} . \mathrm{m}^{3} / \mathrm{min}\right) ;$

$\mathrm{V}=$ volume da câmara de irradiação $\left(\mathrm{m}^{3}\right)$;

$\bar{T}=\frac{T(\text { vent }) \cdot T_{1 / 2}}{T(\text { vent })+T_{1 / 2}}$

com,

$T($ vent $)=\frac{V}{V a z \tilde{a} o}$

$\mathrm{T}_{1 / 2}=$ meia-vida do $\mathrm{O}_{3}$ dentro da câmara de irradiação (min);

Vazão = taxa de extração de ar pela exaustão $\left(\mathrm{m}^{3} / \mathrm{min}\right)$

A equação 1 pode ser entendida como a geração de $\mathrm{O}_{3}$ subtraído do decaimento ao longo do tempo até a condição de equilíbrio.

Para o Irradiador Multipropósito do IPEN/CNEN-SP são conhecidos:

$\mathrm{V}=64 \mathrm{~m}^{3}$, volume da câmara de irradiação;

Vazão $=64,17 \mathrm{~m}^{3} / \mathrm{min}$, vazão projetada para o sistema de exaustão;

$\mathrm{T}_{1 / 2}=11,4 \pm 2,1 \mathrm{~min}$

Considerando ainda a condição estacionária ou de equilíbrio para a produção de $\mathrm{O}_{3}$ onde $\mathrm{C}(\mathrm{t})=\mathrm{C}(\infty)$, e admitindo esta concentração de $\mathrm{O}_{3}$ homogênea e igual entre a câmara de irradiação e a tubulação de exaustão; para $\mathrm{p}=$ taxa de produção de $\mathrm{O}_{3}\left(\mathrm{ppb} \cdot \mathrm{m}^{3} / \mathrm{min}\right)$ obtido a partir de $\mathrm{C}(\mathrm{t})=\mathrm{C}(\infty)$, que torna o valor dentro dos colchetes igual a 1 , teremos $\mathrm{C}_{\text {equilibrio }}=\mathrm{C}(\infty)$ de $\mathrm{O}_{3}$ dado por: 


$$
C_{\text {equilibrio }}=\frac{p \bar{T}}{V}
$$

Assim, encontramos para a taxa de produção de $\mathrm{O}_{3}, \mathrm{p}=7258 \pm 461 \mathrm{ppb} . \mathrm{m}^{3} / \mathrm{min}$ ou $14,5 \pm 0,9 \mathrm{mg} / \mathrm{min}$ de $\mathrm{O}_{3}$. Nesse trabalho foi mantido o fator "ppb" como uma unidade pois o equipamento entregou todas as medidas em ppb e esta é comumente utilizada; mas deve ser lembrado que ppb é adimensional por ser uma proporção entre mesmas unidades. Esse valor foi encontrado utilizando o Irradiador Multipropósito com a atividade máxima, $A=$ 4,92 PBq, com os dois bastidores de fontes expostos, e a partir da respectiva concentração de equilíbrio para essa atividade, $\mathrm{C}_{\text {equilibrio }}=104 \pm 5 \mathrm{ppb}$.

A Figura 19 apresenta os valores da concentração medidos no Irradiador Multipropósito (em preto) e a curva obtida com a equação (1) proposta (em vermelho). A similaridade entre elas demonstrou uma boa adequação da equação proposta para descrever a produção de $\mathrm{O}_{3}$ na instalação do IPEN/CNEN-SP.

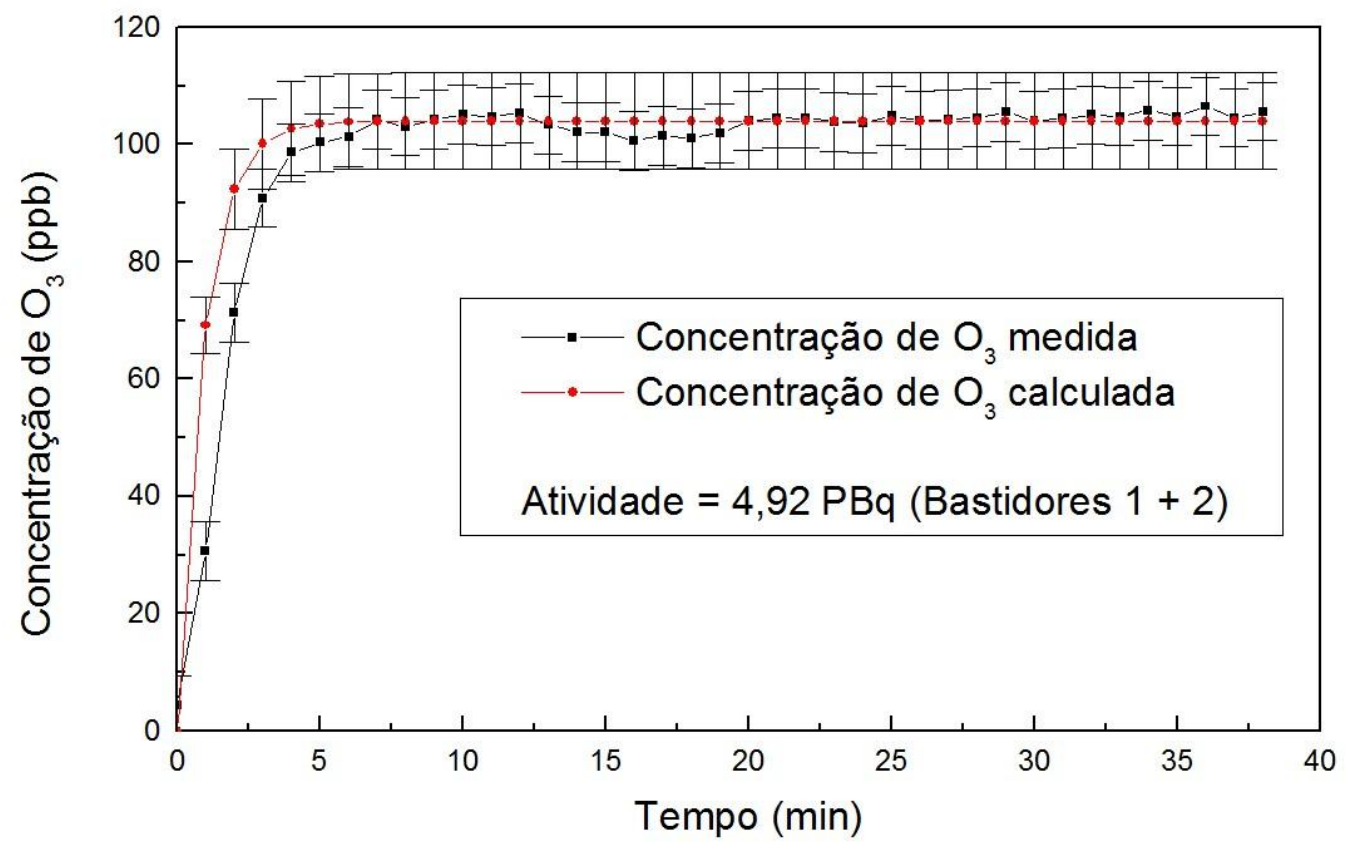

Figura 19 - Concentração de $\mathrm{O}_{3}$ em função do tempo na tubulação de exaustão em condições normais de operação. A curva em preto representam os valores medidos e a em vermelho os valores calculados utilizando a equação (1) proposta. 
Como o irradiador multipropósito do IPEN/CNEN-SP possui dois bastidores de fontes independentes, é possível variar a atividade no interior da câmara de irradiação expondo somente o bastidor 1 , somente o 2 ou 1 e 2 simultaneamente, que na data do experimento valiam $0,82 \mathrm{PBq}, 4,10 \mathrm{PBq}$ e $4,92 \mathrm{PBq}$ respectivamente.

Admitindo que p é função da atividade, foi proposta a seguinte expressão:

$$
p=A \cdot k
$$

onde,

$\mathrm{p}=$ taxa de produção de $\mathrm{O}_{3}\left(\mathrm{ppb} \cdot \mathrm{m}^{3} / \mathrm{min}\right)$;

$\mathrm{A}=$ atividade da fonte exposta $(\mathrm{PBq})$;

$\mathrm{k}=$ constante de proporcionalidade (ppb. $\left.\mathrm{m}^{3} / \mathrm{PBq} \cdot \mathrm{min}\right)$.

Considerando o valor de $\mathrm{p}$ calculado acima foi obtido o valor da constante de proporcionalidade $\mathrm{k}=1476 \pm 94$ ppb.m³/PBq.min. Na Tabela 4 são apresentados os valores da atividade para cada bastidor do irradiador e sua respectiva taxa de produção calculada por meio da equação (3).

Tabela 4 - Valores de taxa de produção de $\mathrm{O}_{3}$ calculados e atividade dos bastidores na data do experimento no Irradiador Multipropósito do IPEN/CNEN-SP.

\begin{tabular}{c|c|c}
\hline Bastidor & Atividade (PBq) & Taxa de produção (ppb.m $\mathbf{3} / \mathbf{m i n})$ \\
\hline 1 & 0,82 & $1210 \pm 77$ \\
\hline 2 & 4,10 & $6052 \pm 385$ \\
\hline
\end{tabular}

Podemos combinar as expressões (1) e (3) para calcular a concentração de $\mathrm{O}_{3}$ entre o início da operação até a condição de equilíbrio. Assim temos:

$$
C(t)=\frac{A k \bar{T}}{V}\left[1-e^{\frac{-t}{\bar{T}}}\right]
$$

onde, 
$\mathrm{A}=$ atividade da fonte exposta $(\mathrm{PBq})$;

$\mathrm{k}=$ constante de proporcionalidade calculada (1476 \pm 94 ppb.m³/PBq.min);

$\mathrm{V}=$ volume da câmara de irradiação $\left(64 \mathrm{~m}^{3}\right)$;

$\bar{T}=\frac{T(\text { vent }) \cdot T_{1 / 2}}{T(\text { vent })+T_{1 / 2}}$

com,

$T($ vent $)=\frac{V}{V a z \tilde{a} o}$

$\mathrm{T}_{1 / 2}=$ tempo de meia-vida do $\mathrm{O}_{3}$ na instalação $(11,4 \pm 2,1 \mathrm{~min})$;

Vazão = taxa de extração de ar pela exaustão $\left(64,17 \mathrm{~m}^{3} / \mathrm{min}\right)$;

$\mathrm{t}=$ tempo de irradiação (min).

Utilizando a expressão (4), foram calculados os valores de concentração de $\mathrm{O}_{3}$ na tubulação de exaustão operando os bastidores 1 e 2 independentemente. Na Figura 20 são apresentadas as curvas de concentração calculadas e medidas na tubulação de exaustão, com esse sistema ligado e com o bastidor 1 exposto. 


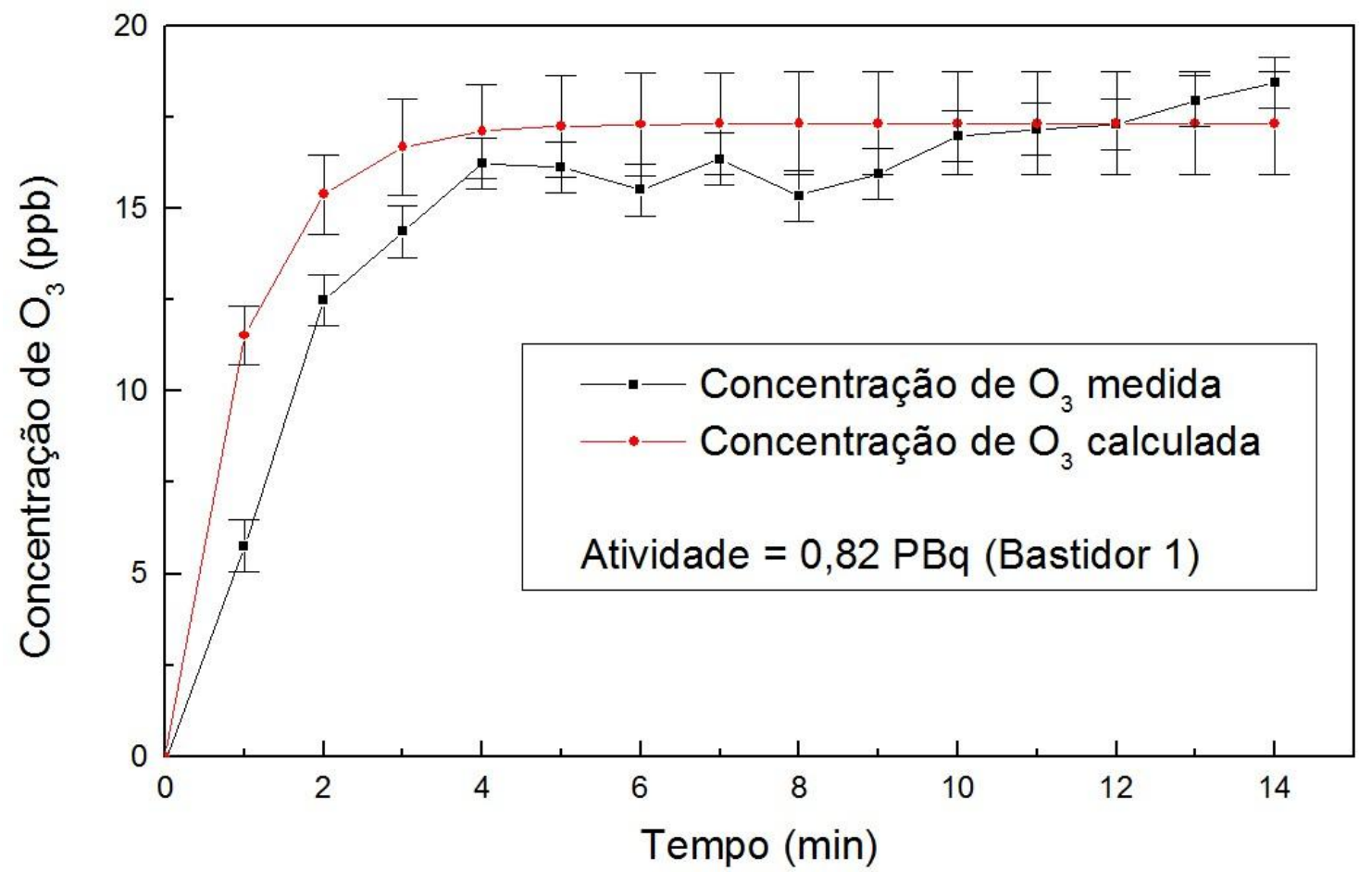

Figura 20 - Valores de concentração de $\mathrm{O}_{3}$ na tubulação de exaustão operando com o bastidor 1. A curva em preto representam os valores medidos e a em vermelho os valores calculados utilizando a equação (4) proposta.

Na Figura 21 são apresentadas as curvas de concentração calculada e medida na tubulação de exaustão, com esse sistema ligado e com o bastidor 2 exposto. 


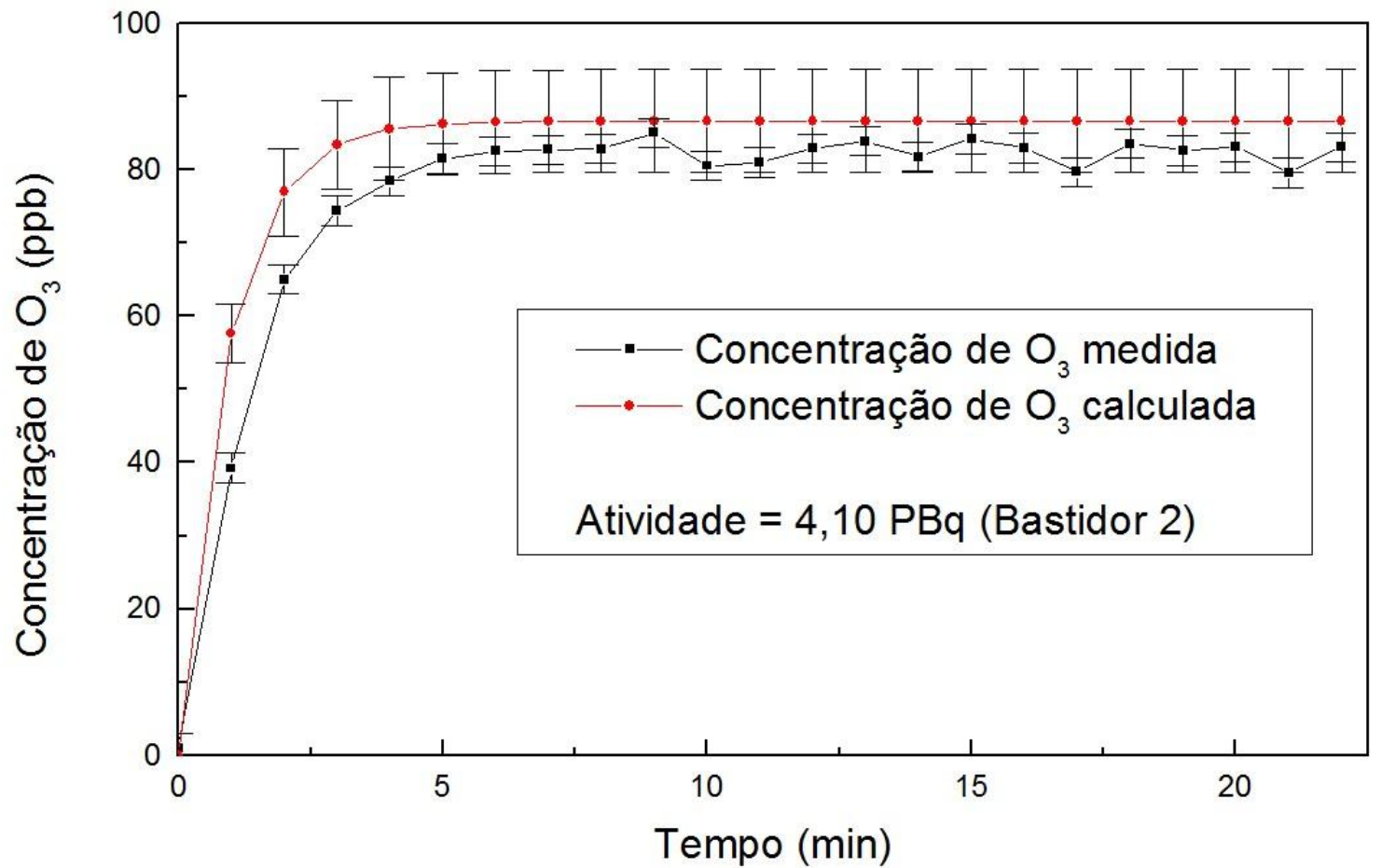

Figura 21 - Valores de concentração de $\mathrm{O}_{3}$ na tubulação de exaustão operando com o bastidor 2. A curva em preto representam os valores medidos e a em vermelho os valores calculados utilizando a equação (4) proposta.

De forma similar, como já calculado anteriormente, mas incluindo agora a proporcionalidade em função da atividade, temos para um tempo de irradiação suficientemente longo a concentração de $\mathrm{O}_{3}$ na condição de equilíbrio derivada da expressão (4) como:

$$
C_{\text {equilbrio }}=\frac{A k \bar{T}}{V}
$$

Na Tabela 5 são apresentados os valores calculados utilizando a expressão (5) para obtenção da concentração de $\mathrm{O}_{3}$ na condição de equilíbrio e comparados aos valores medidos. 
Tabela 5 - Valores de concentração de $\mathrm{O}_{3}$ calculados na condição de equilíbrio e os valores medidos.

\begin{tabular}{c|c|c}
\hline $\begin{array}{c}\text { Atividade } \\
(\mathbf{P B q})\end{array}$ & $\begin{array}{c}\mathbf{C}_{\text {equilíbrio }} \\
\text { calculada (ppb) }\end{array}$ & $\begin{array}{c}\mathbf{C}_{\text {equilíbrio }} \\
\text { medida (ppb) }\end{array}$ \\
\hline 0,82 & $17 \pm 2$ & $17 \pm 1$ \\
\hline 4,10 & $87 \pm 7$ & $82 \pm 2$ \\
\hline 4,92 & $104 \pm 8$ & $104 \pm 5$ \\
\hline
\end{tabular}

\subsection{Medidas em condições normais de operação após o recolhimento das fontes}

$\mathrm{Na}$ Figura 22 são mostradas as curvas do decaimento da concentração de $\mathrm{O}_{3}$ medidas após o recolhimento das fontes. Esses dados foram coletados a partir das tubulações de exaustão com o sistema de exaustão ligado.

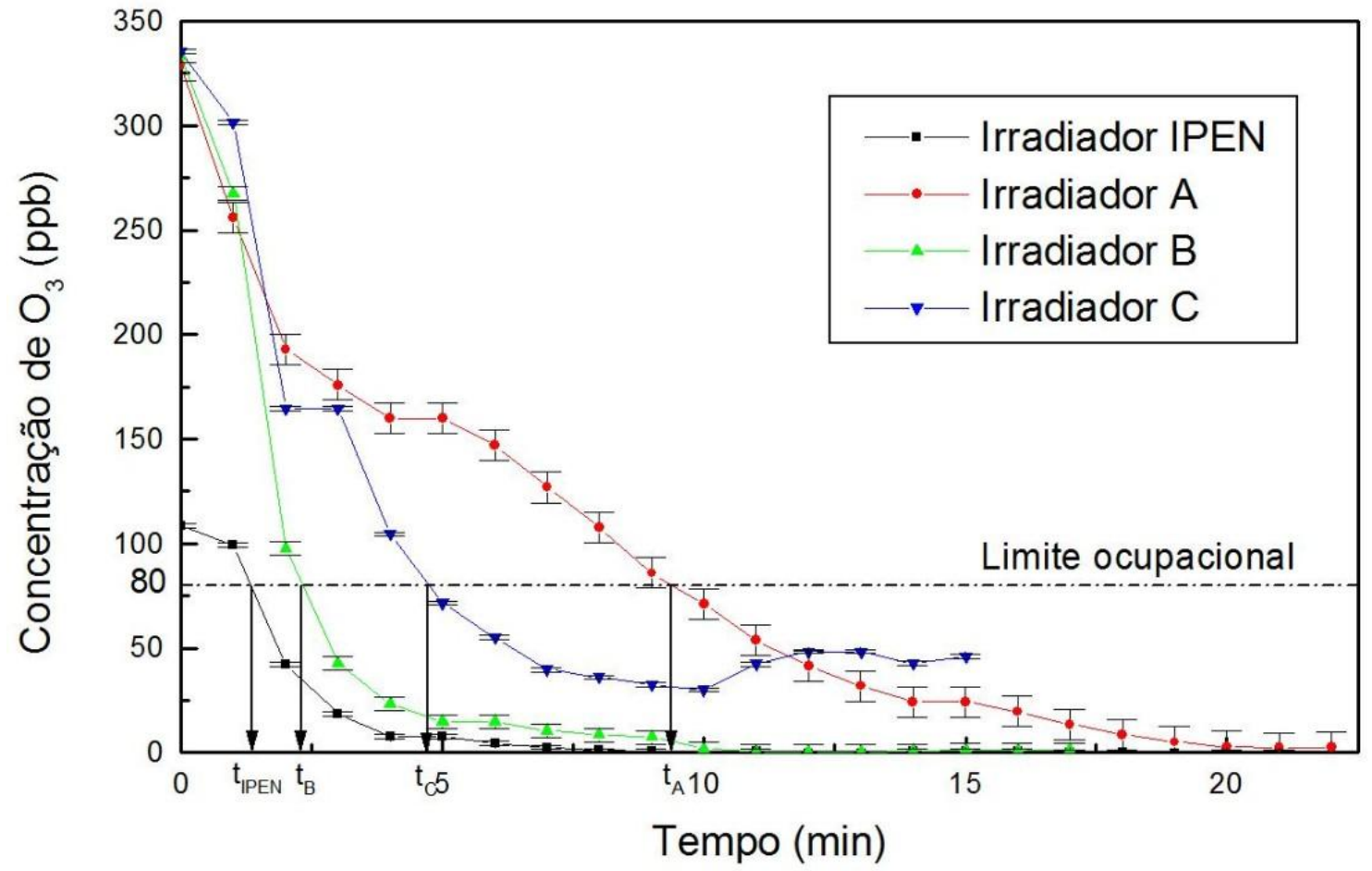

Figura 22 - Curvas de decaimentos da concentração de $\mathrm{O}_{3}$, medidas após o recolhimento das fontes. 
Essas medidas buscaram determinar um tempo adequado para permitir, após o recolhimento das fontes radioativas, o acesso de funcionários à câmara de radiação, de forma a não ficarem expostos a altas concentrações de $\mathrm{O}_{3}$. A linha tracejada na Figura 22 indica o limite de concentração de $\mathrm{O}_{3}$ para trabalhadores, $80 \mathrm{ppb}$, de acordo com a NR15 [28]. Uma tabela do intervalo de tempo do recolhimento das fontes até a concentração do gás atingir o limite ocupacional em cada instalação está apresentado na Tabela 6.

Tabela 6 - Tempo para a concentração de $\mathrm{O}_{3}$ atingir o limite ocupacional nas instalações.

\begin{tabular}{c|c}
\hline Irradiador & Tempo (min) \\
\hline IPEN & 1,3 \\
\hline A & 9,3 \\
\hline B & 2,2 \\
\hline C & 4,7 \\
\hline
\end{tabular}

Vale destacar que nos irradiadores A, B e C, além do sistema de exaustão, as instalações possuem um sistema de insuflamento de ar que não estava ligado e que, se utilizado, reduziria os tempos para acesso às instalações.

Deve ser novamente observado que todos os valores da concentração de $\mathrm{O}_{3}$ nesse trabalho já estão descontados do BG. Assim, esses são tempos que funcionam apenas como indicativos para abertura das instalações considerando o $B G=0$. Infelizmente, devido às elevadas concentrações desse gás encontradas na atmosfera, pode ser que esse valor nunca atinja o mínimo necessário. Em função disso não se indica a utilização de detectores de $\mathrm{O}_{3}$ para liberação da porta de acesso ao interior dessas instalações, já que poderiam impedir o acesso até mesmo sem ter ocorrido qualquer irradiação.

Outro ponto a ser observado é a existência de zonas mortas, com respeito à movimentação de ar no interior das câmaras de irradiação, devido a não homogeneidade das trocas de ar em seus interiores. Esse efeito foi observado e por isso em algumas medidas foi utilizado o circulador de ar no interior da câmara para minimizar esse problema. $\mathrm{O}$ aumento da concentração de $\mathrm{O}_{3}$ na tubulação de exaustão do irradiador $\mathrm{C}$, quando $\mathrm{t}>10 \mathrm{~min}$, como mostrado na Figura 22, pode ser justificado por um movimento tardio dessas massas de ar até o sistema de exaustão. Situações como essa sugerem a 
aplicação de um fator de segurança acrescendo o tempo de abertura das portas para minimizar o efeito e mitigar a possibilidade de exposição de pessoas a concentrações elevadas do gás.

Quanto ao decaimento do $\mathrm{O}_{3}$, várias reações podem ser responsáveis pelo processo. As reações mostradas em I, II, III e IV apresentam alguns desses possíveis mecanismos para a recombinação do $\mathrm{O}_{3}$ a $\mathrm{O}_{2}[14,20,48,61]$ :

I. $\mathrm{HO}^{*}+\mathrm{O}_{3} \rightarrow \mathrm{HO}_{2} *+\mathrm{O}_{2}$

II. $\mathrm{O}_{3}+\mathrm{O}^{*} \rightarrow 2 \mathrm{O}_{2}$

III. $\quad \mathrm{NO}+\mathrm{O}_{3} \rightarrow \mathrm{NO}_{2}+\mathrm{O}_{2}$

IV. $\mathrm{NO}+\mathrm{O}_{3} \rightarrow \mathrm{NO}_{2} *+\mathrm{O}_{2}$

$\mathrm{NO}_{2} * \rightarrow \mathrm{NO}_{2}+\mathrm{h} v$

A reação mostrada em IV, que tem como produto um fóton com comprimento de onda na faixa do infravermelho [61], mostrou-se significativa, pois durante o experimento houve luminescência suficiente para ativar o detector de fumaça da instalação quando a concentração de $\mathrm{O}_{3}$ dentro da câmara de irradiação atingiu aproximadamente $600 \mathrm{ppb}$. $\mathrm{O}$ detector de fumaça utilizado, que opera pela dispersão de fótons na faixa do infravermelho, tornou-se sensível a esta concentração de $\mathrm{O}_{3}$, mostrando a participação da reação apresentada no item IV no processo de decaimento. Esse resultado sugere a viabilidade de utilizarmos detectores desse tipo como indicadores de alta concentração de $\mathrm{O}_{3}$, como um item que viria se somar aos sistemas de segurança das instalações.

\subsection{Medidas da dispersão do $\mathrm{O}_{3}$ para o meio ambiente}

Foram efetuadas medidas da dispersão do $\mathrm{O}_{3}$ no irradiador A, instalação com maior atividade, a uma altura $\mathrm{h}=6,5 \mathrm{~m}$ com relação ao nível do solo e afastando-se do ponto de liberação do sistema de exaustão (chaminé), conforme demonstrado no esquema da Figura 23. 


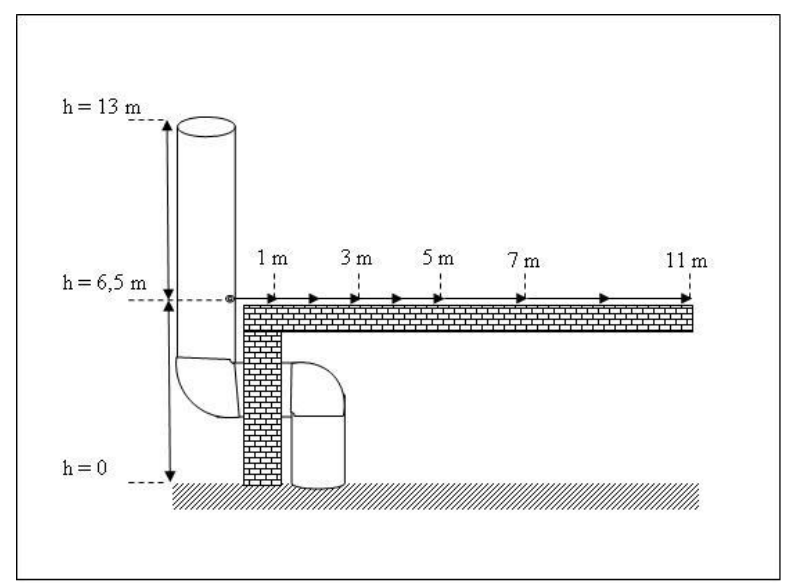

Figura 23 - Desenho representativo das distâncias da coleta de amostras de $\mathrm{O}_{3}$ em relação à torre de exaustão do irradiador $\mathrm{A}$, a uma altura $\mathrm{h}=6,5 \mathrm{~m}$ com relação ao solo.

Essas medidas estão apresentadas na Figura 24.

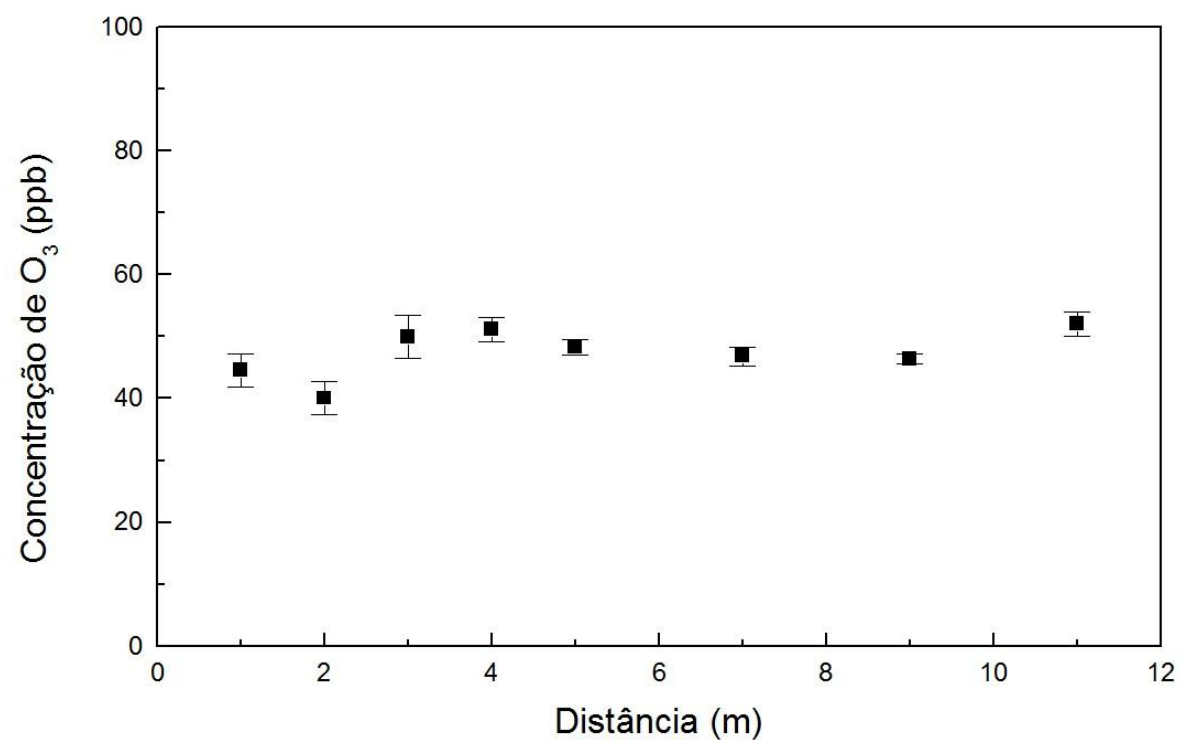

Figura 24 - Concentrações de $\mathrm{O}_{3}$ em função da distância da torre de exaustão no irradiador A, medidas a $6,5 \mathrm{~m}$ de altura em relação ao solo.

Também foram efetuadas medidas no nível do solo, com distâncias de 5 m, 10 m e 15 m em relação à torre de exaustão do irradiador A, conforme desenho na Figura 25. Essas medidas estão apresentadas na Figura 26. 


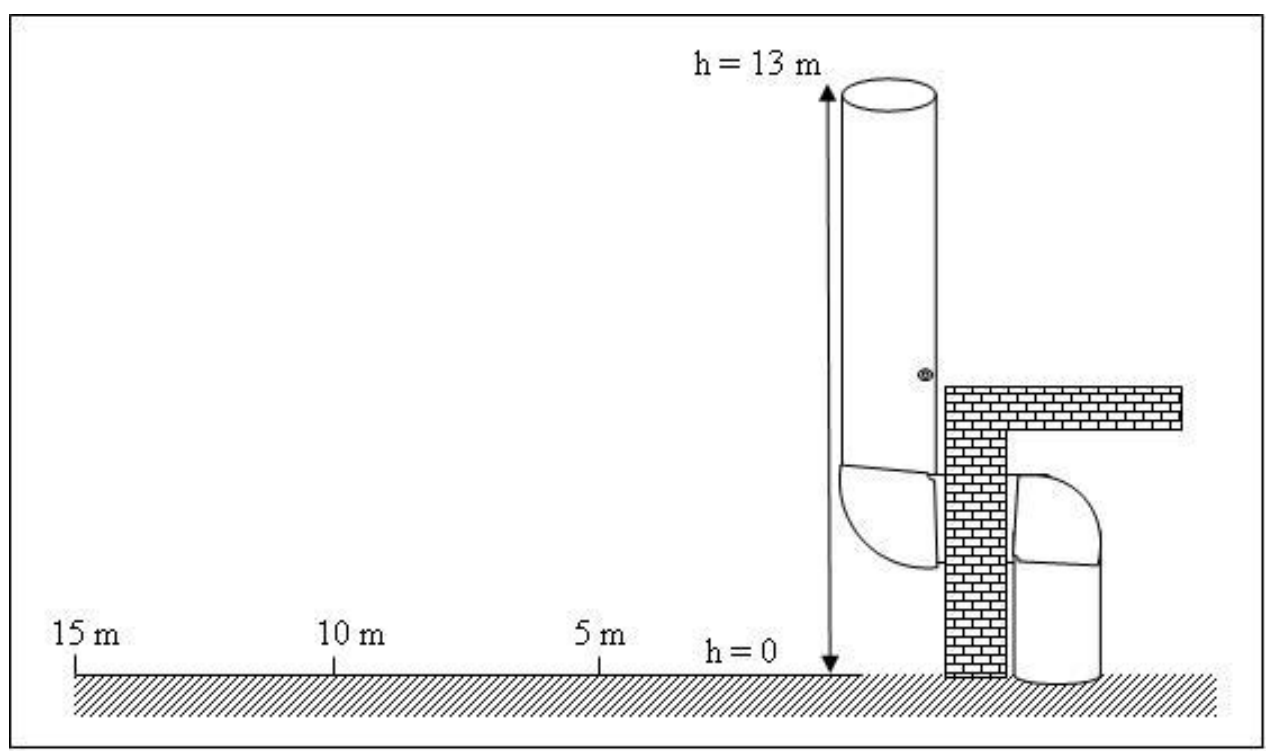

Figura 25 - Desenho das posições medidas, no nível do solo, com relação à chaminé do irradiador A.

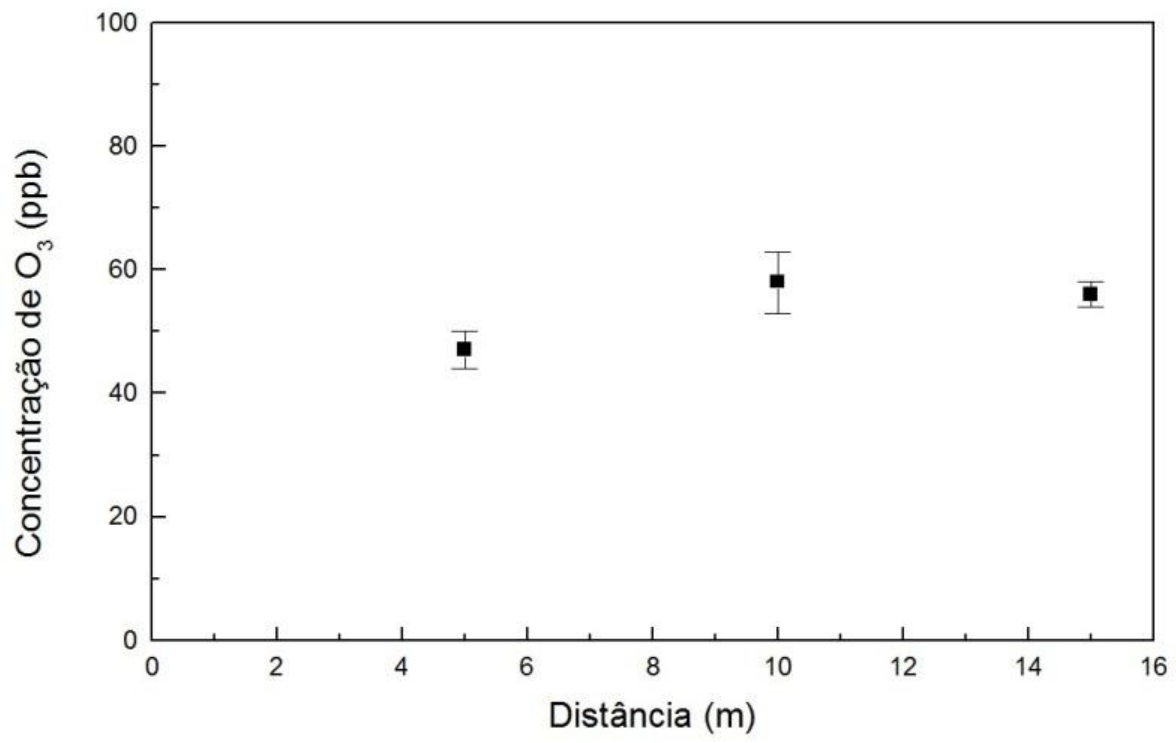

Figura 26 - Concentrações de $\mathrm{O}_{3}$ em função da distância da torre de exaustão no irradiador A, medidas no nível do solo.

Como pode ser observado pelos valores apresentados nas Figuras 24 e 26, dos quais não estão descontados os valores do $\mathrm{BG}$, a dispersão do $\mathrm{O}_{3}$ não permitiu observar a presença de uma pluma em relação à torre de exaustão, devido aos valores encontrados estarem da ordem do BG. 
Do ponto de vista teórico, podemos estimar a dispersão atmosférica do $\mathrm{O}_{3}$ utilizando como referência o cenário mais pessimista de dispersão para um material radioativo, sugerido pela IAEA em seu "Safety Report Series" no 19 [62], que assume a concentração de material radioativo no ponto de interesse como sendo igual à concentração no ponto de liberação (saída de exaustão). Assim temos:

$$
C_{a}=\frac{P_{P} \times Q_{i}}{V}
$$

onde:

$\mathrm{Ca}=$ concentração no nível do solo na direção do vento $\left(\mathrm{Bq} / \mathrm{m}^{3}\right)$;

Qi = média da taxa de liberação para o radionuclídeo i (Bq/s);

$\mathrm{V}=$ fluxo de exaustão no ponto de liberação $\left(\mathrm{m}^{3} / \mathrm{s}\right)$;

$\mathrm{Pp}=$ fração de tempo que o vento sopra na direção do ponto de interesse.

$\mathrm{Na}$ falta de dados relativo à direção dos ventos no ponto de interesse, o documento da IAEA sugere a admissão de $\mathrm{Pp}=0,25$, implicando uma redução de 4 vezes na concentração da emissão gasosa somente pela consideração de que o vento não sopra na mesma direção durante todo o tempo de emissão do gás. Analogamente, considerando a emissão gasosa no irradiador A como a concentração atingida na região de equilíbrio, 357 $\pm 27 \mathrm{ppb}$ e aplicando o fator 0,25 , teremos $89,25 \pm 6,75 \mathrm{ppb}$ para o cenário mais pessimista desse modelo, ainda assim, as Figuras 24 e 26 apresentam valores abaixo de 60 ppb sem o desconto do $\mathrm{BG}$, o que demonstra a rápida dispersão desse gás.

\subsection{Medidas ao longo do diâmetro interno da tubulação de exaustão}

No irradiador multipropósito do IPEN/CNEN-SP foram efetuadas medidas da concentração de $\mathrm{O}_{3}$ ao longo do diâmetro interno da tubulação de exaustão conforme desenho na Figura 27. Os valores das medidas estão apresentados na Figura 28. 


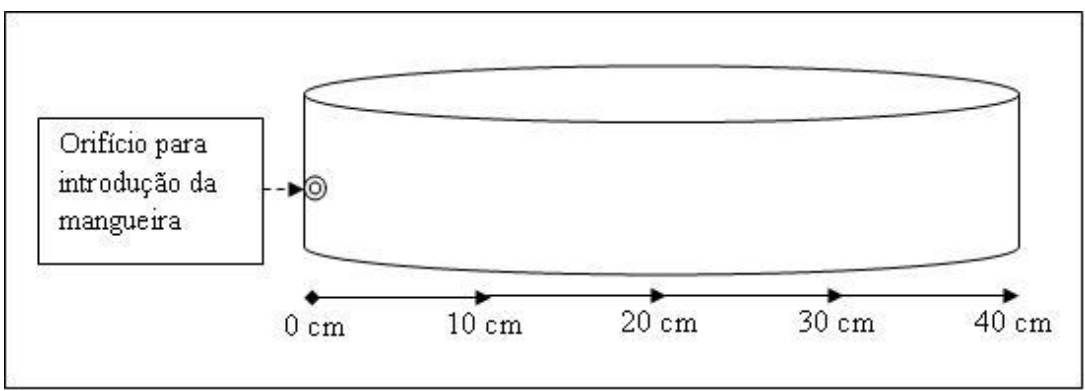

Figura 27 - Desenho das posições de medidas da concentração de $\mathrm{O}_{3}$ ao longo do diâmetro interno da tubulação de exaustão.

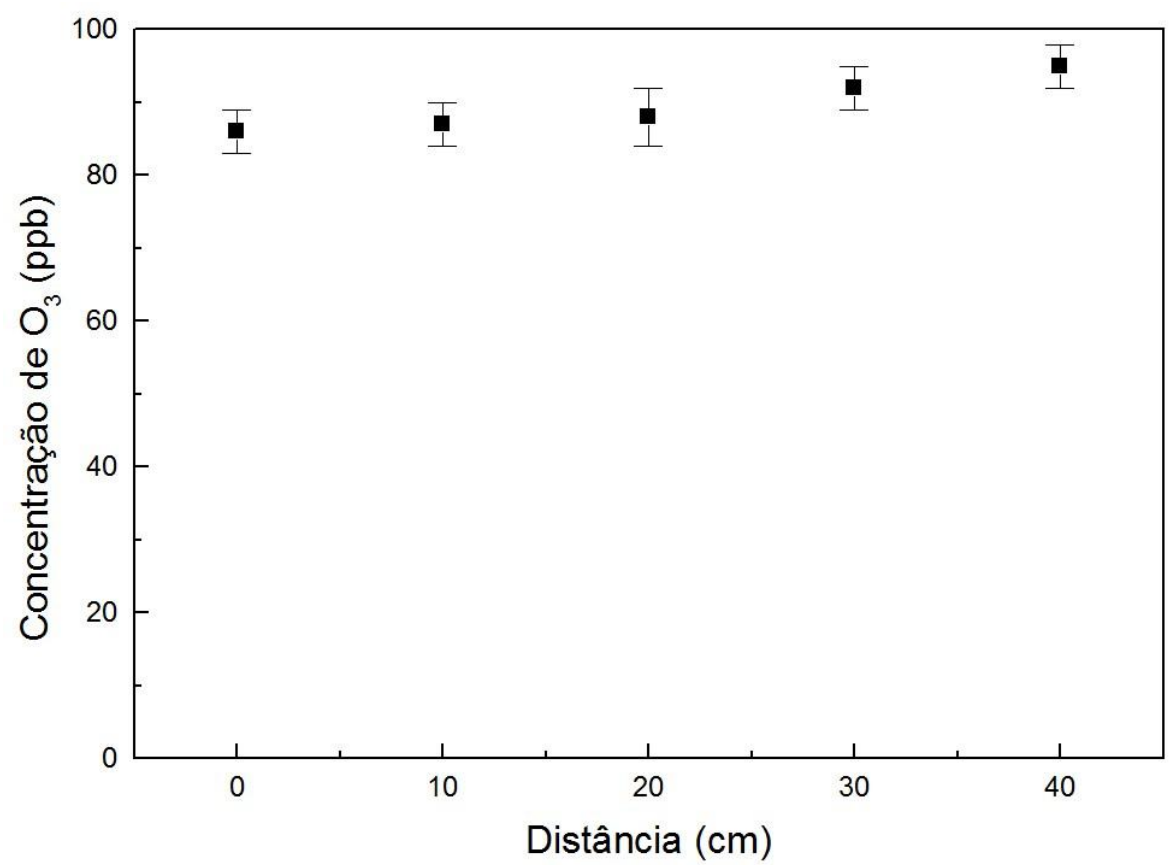

Figura 28 - Concentração de $\mathrm{O}_{3}$ medida ao longo do interior da tubulação de exaustão do Irradiador Multipropósito do IPEN/CNEN-SP.

Essas medidas tiveram como objetivo verificar a existência de uma não homogeneidade da distribuição ao longo do diâmetro do tubo de exaustão que pudesse levar a erros de medição devido ao posicionamento da mangueira de coleta. As pequenas diferenças encontradas nas medidas, que cresceram ao longo do diâmetro da tubulação, são explicadas por um crescimento do valor de BG e não pela não homogeneidade da distribuição de $\mathrm{O}_{3}$ dentro da tubulação. 


\subsection{Medidas ao longo da tubulação de exaustão}

Ainda referente à instalação do IPEN/CNEN-SP foram realizadas medidas de concentração de $\mathrm{O}_{3}$ ao longo da tubulação de exaustão, conforme desenho apresentado na Figura 29. Os pontos A, B, C e D indicam a localização dos pontos de amostragem do gás e na Tabela 7 são apresentados os valores de concentração de $\mathrm{O}_{3}$ obtidos nos referidos pontos.

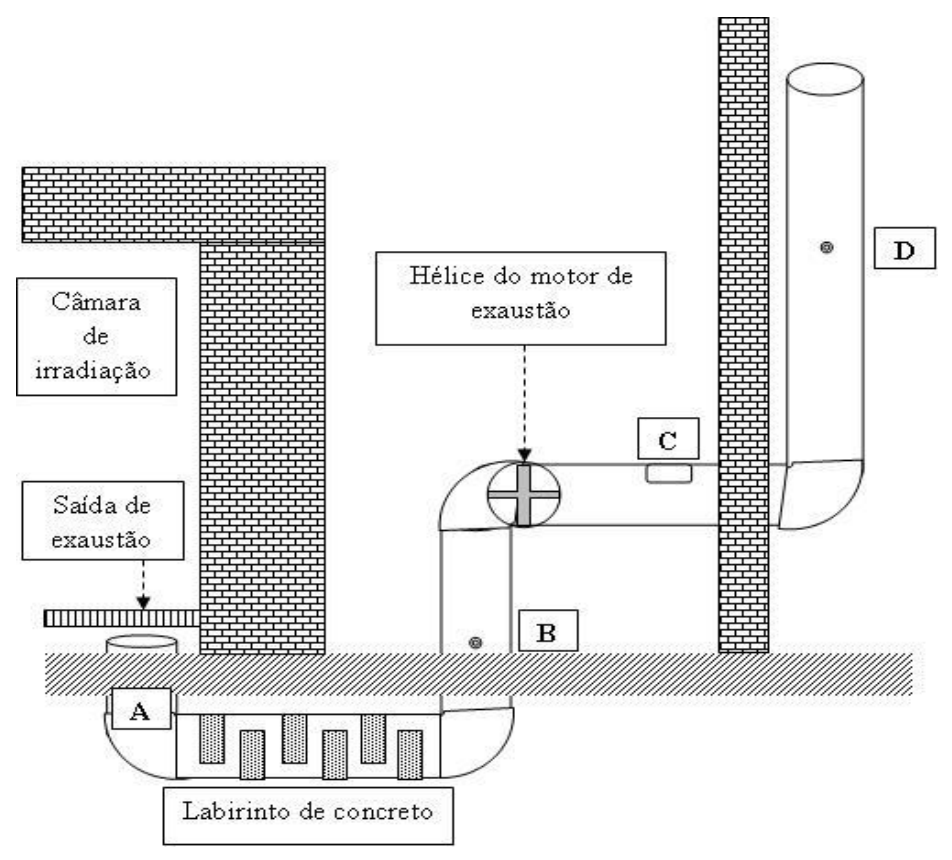

Figura 29 - Desenho dos pontos de coleta para determinação das concentrações de $\mathrm{O}_{3}$ ao longo da tubulação de exaustão do Irradiador Multipropósito do IPEN/CNEN-SP.

Tabela 7 - Valores de concentração de $\mathrm{O}_{3}$ nos pontos amostrados ao longo da tubulação de exaustão do Irradiador Multipropósito do IPEN/CNEN-SP.

\begin{tabular}{c|c}
\hline Ponto & Concentração de $\mathbf{O}_{\mathbf{3}}$ (ppb) \\
\hline A & $92 \pm 4$ \\
\hline B & $85 \pm 4$ \\
\hline C & $81 \pm 2$ \\
\hline D & $80 \pm 2$ \\
\hline
\end{tabular}


Essas medidas tiveram como objetivo verificar uma redução da concentração de $\mathrm{O}_{3}$ por interação do gás com os elementos do sistema de exaustão e, como pode ser observado por meio dos valores apresentados na Tabela 7 , não houve uma redução significativa. Basicamente o $\mathrm{O}_{3}$ pode se decompor ao passar pelo sistema de exaustão apenas no labirinto de concreto e na hélice do motor de exaustão, já que o restante da tubulação foi confeccionada em aço inoxidável e, por tanto, apresenta alta resistência a processos de oxidação. 


\section{CONCLUSÕES E RECOMENDAÇÕES}

A concentração de $\mathrm{O}_{3}$ atinge um valor de equilíbrio após certo tempo de processamento, seja com o sistema de exaustão ligado ou desligado, pelas características das reações químicas de formação e recomposição do ozônio.

O valor de equilíbrio não é linearmente proporcional à atividade da fonte exposta, como foi observado nos irradiadores com altas atividades. Trabalhos anteriores já sugeriram que esse valor não cresce indefinidamente e também não é linear com a taxa de dose, pois a própria radiação destrói as moléculas do gás [32, 37].

Como esperado, a situação ideal é operar o equipamento com ocupação máxima do volume útil, assim haverá menos energia disponível para produção de $\mathrm{O}_{3}$.

Deve-se atentar para produtos em embalagens completamente fechadas e sem vácuo ou controle de atmosfera, pois altos níveis de concentração de $\mathrm{O}_{3}$ podem ser atingidos. Em concentrações elevadas $\mathrm{o}_{3}$ pode atacar o produto processado, especialmente frutas e obras de arte [37, 63, 64]. Os componentes do equipamento também merecem atenção.

As equações propostas descrevem bem o fenômeno de formação de $\mathrm{O}_{3}$ para os valores de atividade disponíveis e considerando as características construtivas do irradiador multipropósito do IPEN/CNEN-SP.

Vale ressaltar que para as demais instalações, as diferenças construtivas dos equipamentos, como possuir porta de entrada e saída de produtos sempre abertas, labirinto e sistema de insuflamento de ar, podem influenciar diretamente no modelo proposto.

Não foi observada nenhuma pluma de concentração de $\mathrm{O}_{3}$ no irradiador $\mathrm{A}$, equipamento com a maior atividade.

As imposições da legislação trabalhista já obrigam que os sistemas de exaustão propiciem 60 trocas de ar por hora para instalações sujeitas a gases tóxicos. Essa condição é atendida em todas as instalações e como foi observado não há uma pluma de $\mathrm{O}_{3}$ 
observável (inclusive na instalação com fontes de maior atividade). Dessa forma conclui-se que os sistemas de exaustão atendem às necessidades de exaustão e dispersão desse gás.

Métodos químicos para a medida de concentração de $\mathrm{O}_{3}$, como o utilizado por Zanibellato et al [43], pelos quais é obtido um valor médio ao longo de uma ou algumas horas de medição, não são apropriados para o estudo realizado neste trabalho, pois foram verificadas variações importantes nos valores de concentração com um medidor em tempo real.

Como sugestão para futuros trabalhos ficam propostos estudos sobre o gás $\mathrm{O}_{3}$ formado considerando situações fora da normalidade (câmara de irradiação vazia e sistema de exaustão desligado) com altas taxas de dose, estudos em outros tipos de instalações, como aceleradores de elétrons e cíclotrons, e estudos envolvendo a emissão de fótons na região do infravermelho durante a decomposição do $\mathrm{O}_{3}$, que podem levar a construção de um monitor de $\mathrm{O}_{3}$ inédito comercialmente. 


\section{REFERÊNCIAS BIBLIOGRÁFICAS}

1. RELA, P. R. Desenvolvimento de dispositivo de Irradiação para tratamento de efluentes industriais com feixe de elétrons. Tese (Doutorado em Ciências). Instituto de Pesquisas Energéticas e Nucleares, São Paulo. 2003.

2. BRYNJOLFSSON, A. Interactions of Gamma-Rays, X-Rays and Fast Electrons with Food and Food Components, Food Preservation Section, Joint FAO/IAEA Division, International Atomic Energy Agency, 1991.

3. BRYNJOLFSSON, A.; MARTINT. G. Bremsstrahlung Production and Shielding of Static and Linear Electron Accelerators below $50 \mathrm{Mev}$. Toxic Gas Production, Required Exhaust Rates and Radiation Protection Instrumentation. International Journal of Applied Radiation and Isotopes, vol 22, p. 29-40, 1971.

4. RELA, P. R. Utilização da Radiação Ionizante na esterilização de produtos médicos e farmacêuticos. Revista da Sociedade Brasileira de Controle da Contaminação(SBCC), edição 4, p. 10-16, 2001.

5. CALVO, W. A. P. Desenvolvimento do sistema de irradiação em um irradiador multipropósito de Cobalto-60 do tipo compacto. Tese (Doutorado em Ciências). Instituto de Pesquisas Energéticas e Nucleares, São Paulo. 2005.

6. CHMIELEWSKI, A. G.; HAJI-SAEID, M. Radiation Technologies: Past, Present and Future. Radiation Physics and Chemistry, v. 72, n. 1-2, p. 16-20, 2004.

7. GEHRING, J. With radiation crosslinking of engineering plastics into the next millennium. Radiation Physics and Chemistry, v. 57, p. 361-365. 2000.

8. UENO, K. The radiation crosslinking process and new products. Radiation Physics and Chemistry, v. 35, p. 126-131. 1990.

9. ROUIF, S. Radiation cross-linked plastics: A versatile material solution for packaging, automotive, electrotechnic and electronics. Radiation Physics and Chemistry, v. 71, p. 525-528. 2004. 
10. GUTTleR, R. A. S.; ENOKIHARA, C. T.; RELA, P. R. Characterization of color centers in quartz induced by gamma radiation. In: International Nuclear Atlantic Conference INAC. Rio de Janeiro, 2009.

11. OMI, N. M. Desenvolvimento de irradiador gama dedicado ao beneficiamento de pedras preciosas. Tese (Doutorado em Ciências). Instituto de Pesquisas Energéticas e Nucleares, São Paulo. 2006.

12. SABATO, S. F.; SILVA, J. M.; CRUZ, J. N.; BROISLER P. O.; RELA, P. R.; SALMIERI, S.; LACROIX, M. Advances in commercial application of gamma radiation in tropical fruits at Brazil. Radiation Physics and Chemistry, v. 78, p. 655658. 2009.

13. RIZZO, M. M.; MACHADO, L. D. B.; BORRELY, S. I.; SAMPA, M. H. O.; RELA, P. R.; FARAH, J. P. S.; SCHUMACHER, R. I. Effects of gamma rays on a restored painting from the XVIIth century. Radiation Physics and Chemistry, v. 63, p. 259-262, 2002.

14. NASA. Studying Earth's Environment From Space. June 2000. Disponível em: < http://www.ccpo.odu.edu/SEES/index.html > Acessado em 23/07/2011.

15. PETER, T. The stratospheric ozone layer - An overview. Environmental Pollution, v. 83, p. 69-79. 1994.

16. BJORN, L. O. Stratospheric ozone, ultraviolet radiation and cryptogams. Biological Conservation, v. 135, p. 326-333. 2007.

17. LUCAS, R. M.; GIES, P. Stratospheric ozone. Encyclopedia of Environmental Health, p. 249-263. 2011. Doi: http://dx.doi.org/10.1016/B978-0-444-52272-6.00169-0.

18. LLOYD, S. A. Stratrospheric ozone depletion. The Lancet, v. 342, p. 1156-1158. 1993.

19. RUTH, J. H. Odor thresholds and irritation levels of several chemical substances: A review. American Industrial Hygiene Association Journal, v. 47, p. 142-151, 1986.

20. PRETTO, A. O estudo do comportamento dos gases-traço $\mathrm{O}_{3}, \mathrm{NO}_{X}, \mathrm{CO}, \mathrm{SO}_{2}$ e de COVs na atmosfera da cidade de São Paulo. Tese (Doutorado em Ciências). Instituto de Pesquisas Energéticas e Nucleares, São Paulo. 2005. 
21. LENGYEL, A.; HÉBERGER, K.; PAKSY, L.; BÁNHIDI, O.; RAJKÓ, R. Prediction of ozone concentration in ambient air using multivariate methods. Chemosphere, v. 57, p 889-896, 2004.

22. GERASOPOULOS, E.; KOUVARAKIS, G.; VREKOUSSIS, M.; DONOUSSIS, C.; MIHALOPOULOS, N.; KANAKIDOU, M. Photochemical ozone production in the Eastern Mediterranean. Atmosferic Environment, v.40, p. 3057-3069, 2006.

23. HAZUCHA, M. J.; LEFOHN, A. S. Nonlinearity in human health response to ozone: Experimental laboratory considerations. Atmospheric Environment, v. 41, p. 45594570. 2007.

24. CAPE, J. N. Surface ozone concentrations and ecosystem health: Past trends and a guide to future projections. Science of The Total Environment, v. 400, p. 257-269. 2008.

25. KLAASSEN, C. D. Casarett and Doull's: Toxicology - The basic science of poisons. 7. ed. McGraw-Hill, 2008.

26. BROMBERG, P.A.; KOREN, H. S. Ozone-induced human respiratory dysfunction and disease. Toxicology Letters, v. 82/83, p. 307-316. 1995.

27. BRASIL. Ministério do Meio Ambiente. Conselho Nacional do Meio Ambiente, Resolução CONAMA n ${ }^{\circ} 03$ de 28 de junho de 1990, publicada no D.O.U. de 22/08/90, Seção I, págs. 15937-15939.

28. BRASIL. Ministério do Trabalho. Norma Regulamentadora NR 15 - Atividades e operações insalubres, portaria $\mathrm{n}^{\circ} 3.214$, de 08 de junho de 1978. Disponível em: < http://portal.mte.gov.br/legislacao/ > Acessado em 23/07/2011.

29. U.S. ENVIRONMENTAL PROTETION AGENCY. Final ozone NAAQS regulatory impact analysis. Air benefit and costs group (C439-02). Research Triangle Park, North California. 2008. (EPA-452/R-08-003).

30. LIND, S. C. Radiation Chemistry of Gases, American Chemical Society: Monograph Series. Reinhold Publishing Corporation, 1961.

31. JOHNSON, G. R. A.; WARMAN, J. M. Formation of ozone from oxygen by the action of ionizing radiations. Discussions of the Faraday Society, v. 37, p. 87-95. 1964. 
32. SEARS, J. T.; SUTHERLAND, J. W.; Radiolytic formation and decomposition of ozone. The Journal of Physical Chemistry, v. 72, p. 1166-1171. 1968.

33. FUEKI, K.; MAGEE, J. L. Reactions in tracks of high energy particles: Radiolysis of oxygen. Discussions of the Faraday Society, v. 36, p. 19-34. 1963.

34. LAMPE, F. W.; WEINER, E. R.; JOHNSTON, W. H.; The formation of ozone in the radiolysis of gaseous oxygen. International Journal of Applied Radiation and Isopotes, v. 15, p. 363-371. 1964.

35. GHORMLEY, J. A.; HOCHANADEL, C. J.; BOYLE, J. W. Yield of ozone in the pulse radiolysis of gaseous oxygen at very high dose rate. Use of this system as a dosimeter. Journal of Chemical Physics, v. 50, p. 419-423. 1696.

36. WILLIS, C.; BOYD, A. W.; YOUNG, M. J.; ARMSTRONG, D. A. Radiation chemistry of gaseous oxygen: experimental and calculated yields. Canadian Journal of Chemistry, v. 48, p. 1505-1514. 1970.

37. SHAH, J.; MAXIE, C. Gamma-Ray Radiosynthesis of Ozone from Air. International Journal of Applied Radiation and Isotopes, v. 17, p. 155-159. 1966.

38. WILLIS, C.; BOYD, A. W.; YOUNG, M. J. Radiolysis of air and nitrogen-oxygen mixtures with intense electron pulses: determination of a mechanism by comparison of measured and computed yields. Canadian Journal of Chemistry, v. 48, p. 1515-1525. 1970.

39. WEILANDICS, C.; ROHRIG, N.; GMUR, N. F. Ozone production due to synchrotron radiation. Nuclear Instruments and Methods in Physics Research, v. A266, p. 691698. 1988.

40. KANDA, Y.; MOMOSE, T.; TAIRA, M. Characterization of radiolytic products from air at a high-energy electron-positron storage ring. Radiation Physics and Chemistry, v. 48, no 1, p. 49-54. 1996.

41. INTERNATIONAL ATOMIC ENERGY AGENCY. Radiological Safety Aspects of the Operation of Electron Linear Accelerators. Technical Reports Series No. 188, Vienna. 1979.

42. DUBEY, P.; SAWATKAR A. R.; SATHE, A. P.; SARMA, K. S. S.; SOUNDARARAJAN, S. Generation of Ozone and Safety Aspects in an Accelerator Facility of Barc, In: Indian Particle Accelerator Conference (InPAC), Fev. 10-13, 2009, 
RRCAT, Indore, Índia. Disponível em: http://inpac.rrcat.gov.in/downloads/inpac/papers/168\%20Praveen\%20Dubey\%20edit.pdf $>$ Acessado em 20/10/2011.

43. Zanibellato, L., Cicoria, G., Pancaldi, D., Boschi, S., Mostacci, D., Marengo, M., Experimental monitoring of ozone production in a PET cyclotron facility, Applied Radiation and Isotopes, Volume 68, Issue 10, p. 1933-1936, October 2010.

44. TAUHATA, L.; SAlATI, I. P. A.; PRINZIO, R.; PRINZIO, M. A. R. R. Radioproteção e Dosimetria: Fundamentos. $5^{\circ}$ revisão, Instituto de Radioproteção e Dosimetria / CNEN, Rio de Janeiro. 2003.

45. EISBERG, R.; RESNICK, R. Física Quântica. 9º ed., Campos. 1994.

46. KNOLL, G. F. Radiation Detection and Measurement. $3^{\circ}$ ed., John Wiley and Sons Inc. 2000.

47. MDS NORDION Inc., Catálogo técnico: C-188 Cobalt-60. Disponível em: < http://www.nordion.com/documents/products/C-188 Brochure.pdf $>$ Acessado em 17/05/2013.

48. SILVA, L. M. Investigação da tecnologia eletroquímica para a produção de ozônio: aspectos fundamentais e aplicados. Tese (Doutorado em Ciências). Faculdade de Filosofia, Ciências e Letras de Ribeirão Preto/USP. Ribeirão Preto. 2004.

49. GEHRINGER, P.; ECHWEILER, H.; FIEDLER, H. Ozone-Electron beam treatment for groundwater remediation. Radiation Physics and Chemistry, v. 46, p. 1075-1078. 1995.

50. ALMEIDA, E.; ASSALIN, M. R.; ROSA, M. A.; DURÁN, N. Tratamento de efluentes industriais por processos oxidativos na presença de ozônio. Química Nova, v. 27, p. 818-824. 2004.

51. JI, G.; ZHANG, B.; WU, Y. Combined ultrasound/ozone degradation of carbazole in APG1214 surfactant solution. Journal of Hazardous Materials, v. 225/226, p. 1-7. 2012.

52. ALENCAR, E. R.; FARONI, L. R. D.; MARTINS, M. A.; COSTA, A. R.; CECON, P. R. Decomposition kinetics of gaseous ozone in peanuts. Engenharia Agricola, v. 31, p. 930-939, 2011. Disponível em $<$ http://www.scielo.br/scielo.php?script=sci_arttext\&pid=S010069162011000500011\&1 
ng=en\&nrm=iso>. Acessado em 17/05/2013. http://dx.doi.org/10.1590/S010069162011000500011.

53. INTERNACIONAL ATOMIC ENERGY AGENCY. Radiation Safety of Gamma, Electron and X Ray Irradiation Facilities. Specific Safety Guide No SSG8. Austria, 2010 .

54. INTERNACIONAL ATOMIC ENERGY AGENCY. Radiation Safety of Gamma, Electron Irradiation Facilities. Safety Series No 107. Austria, 1992.

55. BRASIL. Comissão Nacional de Energia Nuclear. Resolução CNEN ${ }^{\circ} 112$ dispõe sobre o licenciamento de instalações radiativas. Publicada no Diário Oficial da União em 01/09/2011. Disponível em: < www.cnen.gov.br > Acesso em 10/04/2013.

56. TERMO ENVIRONMENTAL INSTRUMENTS INC. Model 49C UV Photometric $\mathrm{O}_{3}$ Analyzer. Instruction Manual. Masachusetts, 1996.

57. CUSTODIO, R.; KUBOTA, L. T.; ANDRADE, J. C. Lei dos Processos de Absorção da Radiação. Universidade Estadual de Campinas. Campinas, 2000. Disponível em: < www.chemkeys.com > Acessado em: 12/04/2013.

58. TERMO ENVIRONMENTAL INSTRUMENTS INC. Model 49C $\mathrm{O}_{3}$ Analyzer, $\begin{array}{lllll}\text { Product } & \text { especifications. } & \text { Disponível }\end{array}$ http://www.thermo.com/eThermo/CMA/PDFs/Product/productPDF 12775.pdf > Acesso em 09/04/2013.

59. BARCELLOS, E. S.; FERREIRA, M. M. C. Um mecanismo plausível para a existência do ozônio noturno. $34^{a}$ Reunião Anual da Sociedade Brasileira de Química, 23-26 de junho, 2011, Florianópolis, SC.

60. Atkis, P.; Jones, L. Princípios de Química: Questionando a vida moderna e o meio ambiente. $5^{\circ}$ ed., Bookman. 2011.

61. ZAFIRIOU, O. C.; TRUE M. B. Interferences in Environmental Analysis of NO by $\mathrm{NO}$ plus $\mathrm{O}_{3}$ Detectors: A Rapid Screening Technique. Environmental Science Technology, v. 20, p. 594-596, 1986. DOI: 10.1021/es00148a008.

62. INTERNACIONAL ATOMIC ENERGY AGENCY. Generic Models for Use in Assessing the Impact of Discharges of Radioactive Substances to the Environment. Safety Report Series no 19. Austria, 2001.

63. CASS, G. R.; NAZAROFF, W. W.; TILLER, C.; WHITMORE, P. M. Protection of works of art from damage due to atmospheric ozone. Atmospheric Environment, v. 25A, no 2, p. 441-451, 1991. 
64. GROSJEAN, D.; WHITMORE, P. M.; MOOR, C. P.; CASS, G. R. Fading of alizarin and related artists' pigments by atmospheric ozone: Reaction products and mechanisms. Environmental Science Technology, v. 21, p. 635-643, 1987. 